\title{
Adult Vascular Wall Resident Multipotent Vascular Stem Cells, Matrix Metalloproteinases, and Arterial Aneurysms
}

\author{
Bruno Amato, ${ }^{1,2}$ Rita Compagna, ${ }^{1,2}$ Maurizio Amato, ${ }^{2}$ \\ Raffaele Grande, ${ }^{3}$ Lucia Butrico, ${ }^{3}$ Alessio Rossi, ${ }^{4}$ Agostino Naso, ${ }^{3}$ Michele Ruggiero, ${ }^{3}$ \\ Stefano de Franciscis, ${ }^{1,3}$ and Raffaele Serra ${ }^{1,3}$ \\ ${ }^{1}$ Interuniversity Center of Phlebolymphology (CIFL), International Research and Educational Program in Clinical and Experimental \\ Biotechnology, Magna Graecia University of Catanzaro, Viale Europa, 88100 Catanzaro, Italy \\ ${ }^{2}$ Department of Clinical Medicine and Surgery, University of Naples "Federico II", 80100 Naples, Italy \\ ${ }^{3}$ Department of Medical and Surgical Sciences, University of Catanzaro, 88100 Catanzaro, Italy \\ ${ }^{4}$ Department of Medicine and Health Sciences, University of Molise, 88100 Campobasso, Italy
}

Correspondence should be addressed to Bruno Amato; bruno.amato@unina.it

Received 28 December 2014; Revised 23 February 2015; Accepted 6 March 2015

Academic Editor: Diana Klein

Copyright (c) 2015 Bruno Amato et al. This is an open access article distributed under the Creative Commons Attribution License, which permits unrestricted use, distribution, and reproduction in any medium, provided the original work is properly cited.

\begin{abstract}
Evidences have shown the presence of multipotent stem cells (SCs) at sites of arterial aneurysms: they can differentiate into smooth muscle cells (SMCs) and are activated after residing in a quiescent state in the vascular wall. Recent studies have implicated the role of matrix metalloproteinases in the pathogenesis of arterial aneurysms: in fact the increased synthesis of MMPs by arterial SMCs is thought to be a pivotal mechanism in aneurysm formation. The factors and signaling pathways involved in regulating wall resident SC recruitment, survival, proliferation, growth factor production, and differentiation may be also related to selective expression of different MMPs. This review explores the relationship between adult vascular wall resident multipotent vascular SCs, MMPs, and arterial aneurysms.
\end{abstract}

\section{Introduction}

The vascular wall is composed of a limited number of different mesodermic cells, endothelial cells (ECs), smooth muscle cells (SMCs), and adventitial stromal fibroblasts. Recent studies have indicated that the human arterial wall also contains resident progenitor cell with angiogenetic properties, known as vascular wall resident progenitor cells (VW-PCs) $[1,2]$. These cells arise during embryonic and fetal age but still remain niched and functional in the adult to guarantee the renewal and repair of vascular tissue and trigger the processes of "postnatal angiogenesis" [3].

Angiogenesis, characterized by the growth of new blood vessels or capillaries from preexisting vessels, plays a pivotal role in the postnatal tissue remodeling both in physiological and in pathological conditions [4]. In this way, studies have shown that matrix metalloproteinases (MMPs) are involved in the degradation of the extracellular matrix (ECM) substrates regulating structural proteins and consequent tissue remodeling and may be considered potential early biomarkers of evolution of vascular and nonvascular disease. But MMPs play a regulatory role and participate in key stages of postnatal angiogenesis as follows: the endothelial proliferation and migration, tub formation with an encased lumen sealed by tight cell-cell junctions, synthesis of ECM proteins, and the recruitment of mural cells stabilizing new connections [5].

Evidences have shown the presence of multipotent stem cells (SCs) at sites of arterial aneurysms; they can differentiate into SMCs and are activated after residing in a quiescent state in the vascular wall [6-8]. The factors and signaling pathways involved in regulating wall resident SC recruitment, survival, proliferation, growth factor production, and differentiation may be also related to selective expression of different MMPs [9-11]. 
The purpose of this review is to examine the role of vascular wall resident stem cells and biomolecular mechanisms that regulate the activity of MMPs in natural history of arterial aneurysms.

\section{Materials and Methods}

PubMed and ScienceDirect databases were searched for articles using the terms adult vascular wall resident stem cells, angiogenesis, MMPs, arterial aneurysms, and chronic inflammation.

Only publications in English were included. Titles and abstracts were screened by 3 authors (Michele Ruggiero, Agostino Naso, and Stefano de Franciscis) to identify potentially relevant studies. All potentially eligible studies were subsequently evaluated in detail by 1 reviewer and 3 authors (Michele Ruggiero, Agostino Naso, and Stefano de Franciscis) through consideration of the full text. Reference lists of retrieved articles were also searched for relevant publications.

Clinical trial, meta-analysis, multicenter study, review, and systematic reviews published in the last 5 years were included. Studies were excluded if they were not in English language, if performed in vitro, if the cohort was defined by the presence of arterial aneurysms and an additional confounding disease process (e.g., chronic renal failure or cerebrovascular diseases), or if arterial aneurysms specific results could not be distinguished from those of a larger population consisting of individuals without disease. Studies were excluded when the primary focus was carotid artery disease, inflammatory diseases, cancer, nonvascular diseases, and treatment with chemotherapy.

\section{Results}

3.1. Study Selection. Initial database searches yielded 75627 studies from PubMed and 362 from Science Direct in the last 5 years. We evaluated 1875 eligible full text articles (Figure 1).

The biology and physiology of vascular wall resident stem cells and their role in postnatal angiogenesis, the current evidences on MMPs activity and their correlation with various stages of angiogenesis, the relationship with MMPs and arterial aneurismal disease, and the association between MMPs, arterial aneurysms, and physiology of vascular wall resident stem cells are given below.

\subsubsection{Adult Vascular Wall Resident Stem Cells and Angiogene-} sis. Many evidences have shown that fetal and adult arterial and venous vessel walls may be niches for various stem and progenitor cells, such as endothelial progenitor cells (EPCs), smooth muscle cell (SMC) progenitors, hematopoietic stem cells (HSCs), mesenchymal stem cells (MSCs), and the socalled mesangial cells, coexpressing both endothelial and myogenic markers [12-15]. Zengin et al. identified VW-PC in human arteries and veins, characterised by expression of CD34+, vascular endothelial growth factor receptor-2 (VEGFR2), and tyrosine kinase with immunoglobulin-like and EGF-like domains 2 (TIE2) and were found in the region between the media and adventitia. These cells have been

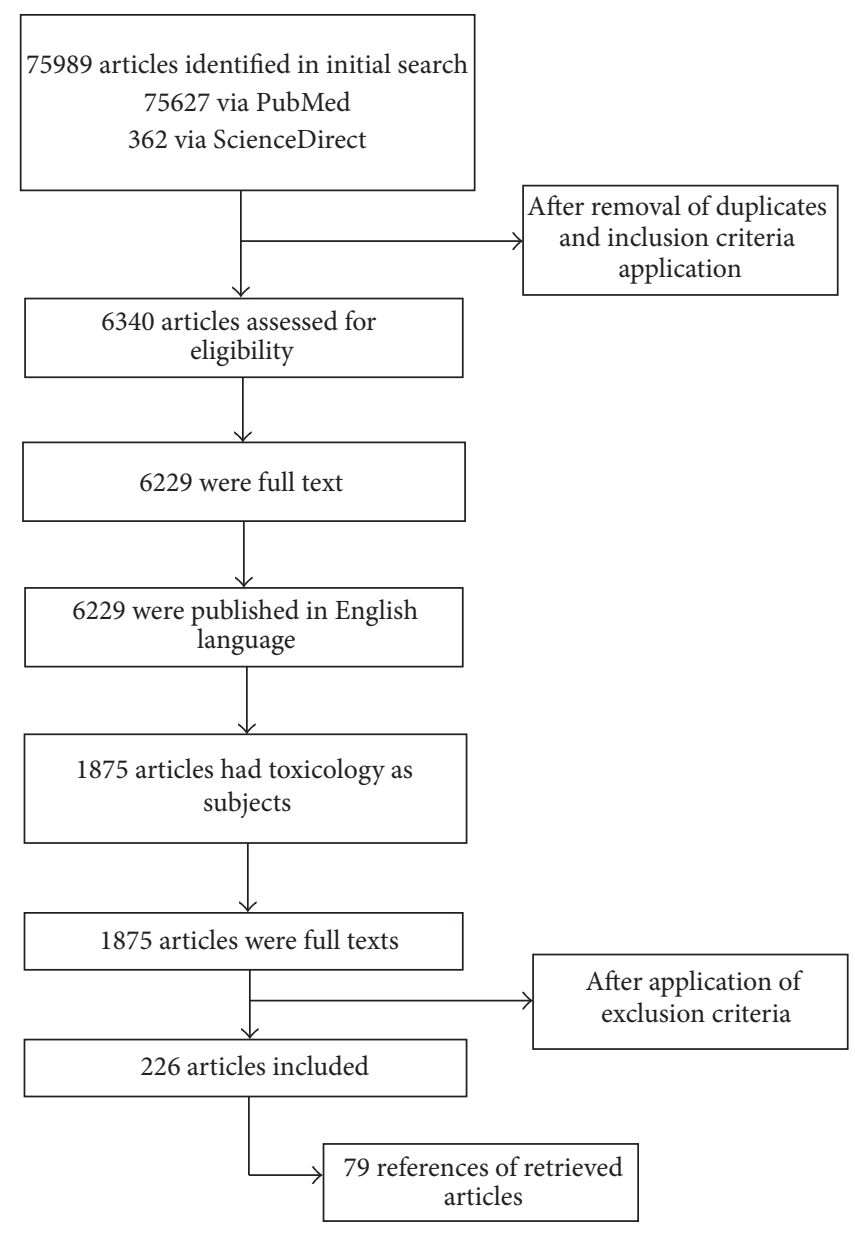

FIGURE 1: Flow of papers identified from search strategy.

found in different layers (intima, media, and adventitia) and they can differentiate into ECs and contribute to new vessel formation in both physiological and pathologic condition $[9,15-18]$. The wall of adult human blood vessels harbours contains not only EPCs but also CD44(+) CD34(-) CD45(-) multipotent MSC-like stem cells, which are capable of differentiating into pericytes/SMC and covering endothelial cell layers of newly formed blood vessels in vitro and in vivo [19]. This zone was identified in human adult vessels as a niche for CD34+ CD31- EPCs and for progenitors of macrophages earlier. Later, it was shown that CD34(+) Scal(+) cells cluster in a domain of Sonic hedgehog signaling which was restricted to the inner part of mouse arterial adventitia similar to the vasculogenic zone [20]. Vasculogenic zone in the wall of vessels acts as a source of progenitor cells and is in relation to those of EPCs circulating in peripheral blood or derived from the bone marrow [21] but it also serves as a reservoir for inflammatory cells important for local immune response. VW-PCs reside in this zone from the developmental embryonic to adult phase and have the capacity to differentiate into SMC and pericytes and are able to form capillary sprouts and migrate towards angiogenic lineage [18]. 
Vasculogenesis is defined as de novo vessel formation induced by differentiation of angioblasts and it is the major mechanism of formation of blood island vessels, dorsal aorta, endocardium, and vitelline vessels in the embryo. Angiogenesis is defined as outgrowth of new vessels from preexisting blood vessels and vascular growth and remodeling are key events in the adaptation of arteries to physiological and pathological environmental stimuli [22]. Several steps of this process are endothelial cell migration, proliferation, and tube formation [23-25].

VW-PCs normally involved in physiological vascular homeostasis might also act as reservoir of undifferentiated cells ready to supply the cellular demands and acquiring local phenotypic characteristics [26]. The active cellular component in these processes is granted by endothelial lineage cells, but neovascularization does not only depend on endothelial cell migration and proliferation with subsequent formation of endothelial tubes; it also requires pericyte coverage of vascular sprouts for vessel stabilization and survival; these cells were capable of differentiating into vascular SMCs and pericytes under in vitro and in vivo conditions [27]. MSCs may represent an important source of pericytes and SMCs during angiogenesis under physiological and pathological conditions. Evidences show that these cells migrate to the vascular injury sites in postnatal life to replace dead or dysfunctional cells [28-31].

3.1.2. Vascular Wall Resident Cells and Aneurysms. Aneurysmal disease is one of the most common clinical diseases in Western countries [32] and is related to the presence of multiple risk factors such as alterations of glucose and lipid metabolism, hypertension, trauma, anastomotic disruption, infections, and connective or inflammatory diseases. As described previously [32], arterial aneurysms can be divided into central aneurysms, such as abdominal aortic aneurysms, and peripheral aneurysms, such as aneurysms of the popliteal, femoral, and carotid arteries [32].

Arterial aneurysms are caused by two combined mechanisms that lead to progressive medial degeneration and vessel dilation: increased degradation by MMPs [33] and decreased synthesis of elastin caused by apoptosis of vascular SMCs [34]. Moreover, chronic inflammation and consequent oxidative stress promote progressive vascular wall impairment [35]. As described above, recent studies have shown that the wall of adult blood vessels itself can be considered as reservoir for resident stem cells [18, 36, 37]. These VWPCs largely reside in the "vasculogenic" area giving birth to generation of pericytes/SMCs which are involved in the formation of new vessels and can be activated by endothelial injuries or other vascular insults undergoing changes that include proliferation, differentiation, and migration $[38,39]$. VW-PCs could aggregate at sites of injury and differentiate into ECs or move across vascular wall towards the intima and differentiate into SMCs [40]. Moreover, differentiation and behaviour of VW-PCs are regulated by adventitia through releasing factors involved in the regulation of wall functions [40]. In many conditions, such as presence of atherosclerotic plaques or injury, resident stem cells are activated and stimulated to acquire specific structural and functional behaviour [41, 42], so the vasculogenic area is thought to be also a niche of undifferentiated cells acquiring specific phenotypic characteristics and during the development of pathologic conditions affecting the vessel walls [41]. In order to fulfill their duties, these cells have to be mobilized and released from their niches. Some studies suggest that specific inflammation of adventitia leads to the production of cytokines or enzymes such as tumor necrosis factor alpha (TNF- $\alpha$ ), transforming growth factor beta (TGF- $\beta$ ), granulocyte colony stimulating factor (G-CSF), granulocyte macrophage colony stimulating factor (GM-CSF), monocyte chemoattractant protein-1 (MCP-1), and stromal cell derived factor 1-alpha (SDF1- $\alpha$ ), all factors able to promote SCs mobilization towards sites of injury via vasa vasorum [4146]. The relation between arterial aneurysms and VW-PC is hypothesized. Ryer et al. described a possible proinflammatory role of stem cells in abdominal aortic aneurysms and it was observed in infrarenal aortic wall specimens collected from patients with abdominal arterial aneurysms (AAA) undergoing surgical repair; a significantly great number of ckit+ and CD34+ cells also express macrophage marker CD68 but not the SMCs marker SM22 or the fibroblast marker FSP1. Moreover CD68+ cells colocalized with the cellular marker of proliferation Ki67 [36]. These findings suggest an inflammatory/immune role of resident stem cells in AAA pathogenesis and were also confirmed by other authors [47, 48].

Studies showed that altered hemodynamical forces probably affect resident stem cells differentiation. In particular, shear stress can stimulate these resident stem cells to differentiate into endothelial lineage whereas cyclic strain leads to smooth muscle differentiation. So disturbed blood flow and distorted biomechanical stress can lead to abnormal differentiation of vascular stem cells whose altered behaviour may lead to the development of vascular wall diseases, such as arterial aneurysms [39].

3.2. Biology of MMPs. MMPs, a group of zinc dependent proteinases consisting of 28 family members, play important roles in ECM degradation as well as in the cleavage of other proteins such as growth factor and cytokines [49] and it is critical for all aspects of vascular biology [50]. Serra et al. have shown that MMPs are implicated in main vascular diseases [5, 51-64]; MMPs have been implicated in physiological and pathological angiogenesis because of their fundamental nature in ECM metabolism and remodeling. During the onset of angiogenesis, this basement membrane matrix is degraded by proteinases to allow endothelial cell to migrate and various angiogenesis promoters and inhibitors such as growth factors, chemokines, growth factor receptors, adhesion molecules, and apoptosis mediators to be released from ECM [65-67].

3.2.1. MMPs as Regulatory Molecules of Vascular Wall Resident Stem Cells. VW-PCs are capable of differentiating into pericytes and smooth muscle cells (SMCs) $[68,69]$. Pericytes synthesize basement membrane matrix proteins, proteoglycans, such as decorin, biglycan, versican, aggrecan, and fibronectin 
and various collagens [70]. Tightly wrapped around the vessels, pericytic MSCs interact with another critical regulator of the vascular environment, the vascular basement membrane (VBM) [71, 72]. The VBM is a specialized extracellular matrix that surrounds the blood vessels of the body and is regulated through a control system involving proteases, which alter and degrade the matrix, and protease inhibitors, which maintain and protect the VBM from disruption. This interplay between proteases and protease inhibitors as well as its effects on the VBM profoundly influences vessel stability and, hence, many physiological and pathological processes, such as aneurysmal disease [73-77]. The pericyte-EC interface is rich in fibronectin deposition and contains tight and gap junctions as well as $\mathrm{N}$-cadherin and b-catenin-based adherens junctions [78]. Fibronectin is concentrated at the pericyte-EC interstitium and its degradation by proteolytic enzymes such as MMPs gives rise to biologically active fragments [78]. Among these, a $45 \mathrm{kDa}$ fibronectin fragment inhibits EPCs proliferation and stimulates pericyte and SMC proliferation, suggesting a role for this fragment in vessel maturation [79].

MMPs are probably the most important family in ECM remodeling and it is known that the cleavage of ECM liberates angiogenic factors [80-83]. SMCs can constitutively express and secrete MMP-2, and expression and secretion of MMP9 are inducible in SMCs under the control of NF-kB; they express MMP-7 and MMP-3. Moreover, MMPs released by leucocytes and convected circulating plasma MMPs represent other important sources of MMPs in the arterial wall. SMCs are, in parallel, the main source of tissue protease inhibitors and also the possible target of blood-borne protease zymogens convected through the wall, retained or not, and directly or indirectly activated on contact with the SMCs $[84,85]$. They also constitutively express and secrete several serine proteases, such as tissue-type plasminogen activator (t-PA), for which expression can be enhanced by numerous stimuli $[86,87]$. Thus, in the vascular wall, SMCs are the main source of TIMPs and of several serpins, such as plasminogen activator inhibitor-1 and protease nexin-1 (PN1) and probably cysteine inhibitors (cystatin) [88]. MMP9 can convert normal nonangiogenic islets into angiogenic islets. More recently, it was reported that ectopic expression of Homeobox C11 (HOXC11), which is normally restricted to the SMCs of lower limbs vessels, in carotid arteries, aortic arch, and descending aorta, results in drastic vessel wall remodeling including elastic laminae fragmentation, SMC loss, and intimal lesion formation $[89,90]$. These results suggest direct transcriptional control of two members of the matrix MMPs family, including MMP-2 and MMP-9 that are known as key players in the inception and progression of vascular remodeling events.

Many evidences have shown that the influence of a particular MMP may depend on the vascular bed analyzed or on a particular type of EPCs and its related receptor, and biophysical parameters (substrate elasticity, cell stiffness or cell shape, and vascular ischaemic injuries) can also promote the release of the serine proteases cathepsin $G$ (catG) and neutrophil elastase (NE) and the secretion of the collagenase. MMP-8 and MMP-9 initiate a cascade of events including inactivation of retention factors, release and activation of mobilizing factors and cytokines, ECM degradation and remodeling with breakdown of cell-matrix interactions, and also breakdown of cell-cell contacts, ultimately resulting in stem cell egress; moreover, the reduction of endogenous protease inhibitors may also contribute to the highly proteolytic activity [91-93].

MMPs are also related to mitogenesis and migration of SMCs [92]. In in vivo studies, MMP-3 knockout mice reduced neointima formation after carotid ligation and also attenuated SMC migration into wound [94]. SMCs are important both to promote arterial remodeling and to modify vessel diameter and/or wall thickness to ensure adequate tissue perfusion [95].

In presence of VEGF, arterial wall resident cells became round-shaped, resembling ECs, and part of the cells acquired CD-31, VE-cadherin, and von Willebrand factor expression, whereas when they are cultured with TGF $\beta-1$ or plateletderived growth factor-BB (PDGF-BB) adopted a rather elongated phenotype, similar to that of SMCs, and part of the cells acquired anti- $\alpha$-smooth muscle actin (ASMA) and calponin [96]. VEGF also induces the expression of Notch1 through PI3K/AKT pathway in cultured ECs [97]. The roles of Notch include the differentiation in both EPCs and SMC via activation of transcriptional CBF-1/RBP-J $\kappa$-dependent and independent pathways and transduction of downstream Notch target gene expression $[98,99]$. These angiogenic factors can induce differentiation from progenitor in media to EPCs and SMCs [9].

Recently it has been shown that pericytes are able to detach from the vascular wall and contribute to fibrosis by becoming scar-forming myofibroblasts in many organs including the kidney. At the same time, the loss of pericytes within the perivascular compartment results in vulnerable capillaries which are prone to instability, pathological angiogenesis, and, ultimately, rarefaction such as aneurysmal disease $[100,101]$.

Based on these evidences, we could affirm that MMPs may play a central role to regulate the activity of the VWPCs by increasing the biodisponibility of main proangiogenic factors. Another role of MMPs is to promote the differentiation and migration of fibroblast and resident vasculogenic progenitors critically involved in vascular repair by remodeling of ECM [102]. MMPs contribute to VW-PCs during the progression of arterial aneurysms and participate in all crucial stages of this degenerative disease.

\subsubsection{Vascular Wall Resident Stem Cells in Natural History of} Arterial Aneurysms: A Debate Still Open. As widely known, the pathogenesis of aneurysm involves inflammation, protease activation, ECM remodeling, and SMC dysfunction and apoptosis leading to the weakness of the vessel wall and arterial expansion under the influence of blood pressure [34]. Aneurysm complications, as rupture, dissection, and distal embolization, are frequent and with a high morbidity rate and an increase with the diameter of the vessel $[103,104]$.

Clinically, guidelines recommend surgical treatment for large aneurysms and monitoring for smaller aneurysms [103]. 
However, a significant number of small aneurysms, falling outside the criteria for surgical treatment, undergo complication development [104]. The identification of small aneurysms at increased risk of complications may improve the morbility and morbidity associated with this disease.

3.3. MMPs and Arterial Aneursysms. An association between arterial aneurysms and MMPs has been described in both central $[58,105,106]$ and peripheral arterial diseases $[107-$ 118]. MMPs regulate extracellular structural proteins and tissue remodeling and are involved in several vascular diseases $[4,51,119]$. We have documented a significant correlation between age, median size of aneurysms, and plasma levels of both MMP-9 and neutrophil gelatinase-associated lipocalin (NGAL) in both central and peripheral aneurysms [32]. Degradation of ECM by MMPs allows the migration of vascular smooth muscular cells from the medial vascular layer to the intimal layer [51, 120-124]. These proteinases, degrading elastin, can induce a compensatory fibrosis and inflammation with destruction of all major matrix components, excessive distension, and rupture $[125,126]$. Several cytokines and growth factors including IL-1a and b, IL-2, IL-17, insulin like growth factor-1, transforming growth factor alpha (TGF$\alpha$ ), and tumor necrosis factor alpha-a (TNF- $\alpha$ ) can induce MMPs and NGAL, a marker of neutrophil activation that can modulate MMP-9 activity [58].

3.3.1. Vascular Wall Resident Stem Cells and Aneurysms: Positive and Negative Effects. The role of VW-PCs in aneurismal formation is relatively unknown and remains controversial. Witte et al. showed that VW-PCs present intracytoplasmatic vacuoles as a sign of their inherent capacity to form a capillary lumen. It depends on local environment whether these cells undergo a differentiation or necrosis; maybe these cells undergo necrosis when red blood cells penetrate into their intracytoplasmatic vacuoles [127]. VW-PCs express STRO1, c-Kit, and CD34 and, in response to tissue injury, can differentiate into SMCs and fibroblasts suggesting an active role in a repair and remodeling process [128]. C-kit cells can induce the secretion of angiogenic cytokines such as VEGF stimulating their proliferation and differentiation into ECs and MSCs [128].

The basic phenomena in the pathogenesis of arterial aneurysms are degradation of ECM components with increased MMPs and loss of structural integrity of the arterial wall $[129,130]$. These pathologic changes are associated with chronic inflammation of aortic walls, where resident vascular SMCs and infiltrating macrophages release MMPs, particularly MMP-2 and MMP-9 [131, 132]. MSCs have also been reported to upregulate elastin and downregulate collagen gene expressions in fibroblasts and are known to participate in remodeling associated with vascular injury in a variety of settings $[133,134]$. In arterial aneurysms, the medial fiber network is impaired, SMC number diminishes, and inflammatory cells invade the expanding vascular wall. The ECM alteration in the aortic wall depends on the balance between ECM synthesis from vascular SMCs and protease production by SMCs and inflammatory cells. As previously described, VW-PCs can be mobilized from adventitia to the media and differentiate to SMC in cases of injury or damage of the arterial wall cells in order to replace them. Moreover, the chronic exposition to inflammatory conditions such as natural history of aneurysmal disease [135-137] can determine failure of SMC recruitment and migration along developing vessels can lead to vascular instability and regression, an event that is likely due in part to the ability of these cells to secrete and organize extracellular matrixcontaining basement membranes and elastin [18, 138-140]. In this view, human autopsies have demonstrated the presence of CD34+Scal+CD133- cells within neointimal lesions and the adventitia of atherosclerotic plaques, which may be a source of endothelial and vascular smooth muscle cells that form atherosclerotic lesions [141-144]. Recently, Tigges et al. and other groups reported that adventitial multipotent pericytes participate in the restenotic response in mice with femoral arterial injuries [40,145]: pericytes are increased in adventitia in response to vascular injury and contribute to restenosis in injured arteries. Pericytes have mesenchymal stem cell like features and are potentially an important cellular source that contributes to intimal hyperplasia in rat aortic allograft models with transplantation-derived arteriosclerosis $[146,147]$. Many factors including cytokines such as TNF$\alpha$, IL-1, IFN- $\gamma$, and toxins of infectious agents and hypoxia can stimulate the release of many growth factors by MSCs, including EGF, FGF, PDGF, TGF-b, VEGF, hepatocyte growth factor (HGF), insulin growth factor-1 (IGF-1), angiopoietin1 (Ang-1), keratinocyte growth factor (KGF), and stromal cell derived factor-1 (SDF-1) $[148,149]$. These growth factors, in turn, promote the development of fibroblasts, endothelial cells, and tissue progenitor cells, which carry out tissue regeneration and repair.

Thus, VSMCs, the predominant cell type of the media, are capable of robust proinflammatory responses to diverse stressors. The multiple cytokines and chemokines produced within the media can profoundly affect macrophage and $\mathrm{T}$ cell function; on the other hand, VSMCs and the ECM are able to have significant anti-inflammatory properties. The balance between the pro- and anti-inflammatory effects of VSMCs and their extracellular matrix versus the strength of the inciting immunologic events determines the pattern of medial pathology. Limitations on the extent of medial infiltration and injury defined as "medial immune privilege" are typically seen in arteriosclerotic diseases, such as atherosclerosis which is the first step of aneurysmal disease. Conversely, the breakdown of medial immune privilege that manifests as more intense leukocytic infiltrates, loss of VSMCs, and destruction of the extracellular matrix architecture is a general feature of certain aneurysmal diseases and vasculitides [150, 151]. Tissue injury is always associated with the activation of immune/inflammatory cells, not only macrophages and neutrophils but also adaptive immune cells, including CD4+ T cells, CD8+ T cells, and $\mathrm{B}$ cells, which are recruited by factors from apoptotic cells, necrotic cells, damaged microvasculature, and stroma $[152,153]$. Insufficient inflammatory cytokines during chronic inflammatory sites, however, could stimulate MSCs to produce chemokines and tropic factors in absence of sufficient immune inhibitory 
factors. As such, chronic inflammation may lead MSCs to protract the disease recovery or even worsen the disease course such us in aneurysmal disease $[154,155]$.

Specifically, progenitor cells can contribute to calcification as bone marrow (BM) contains both osteoblast and osteoclast precursors termed as osteoprogenitors (OPs) associated with bone remodeling [156]. This novel mechanism was named "circulating cell theory." The bone marrow derived cell population may seed the arteries and contribute to disease or repair $[156,157]$. Another common mechanism that can explain the recruitment of circulating OPs in arteries is homing; in response to stress signal, injury, inflammation, repair, or abnormal cytokine signaling, circulating cells cross the endothelium and invade the target tissue $[157,158]$. The endothelial phenotype selectively modulates bone marrow derived stem cells homing: indeed different endothelial phenotypes hold functional differences. As an example, coronary artery endothelium enables the fastest bone marrow stromal cells integration. Transmigration requires the interaction of vascular cell adhesion molecule-1, very late antigen- $4, \beta 1$ integrins, MMPs secretion, and cytokines $[159,160]$. Moreover pericytic myofibroblasts expressed BMP-2, a powerful bone morphogen. Recently it was hypothesized that MSC might play a role in the pathogenesis of atherosclerosis, and it was demonstrated that, under particular conditions, MSC in culture acquires an osteoblastic phenotype via the activation of the Wnt pathway $[161,162]$. In hyperlipidemic rats treated with angioplasty to have a vascular damage, MSC started the vessel wall remodeling and triggered calcification, mediated by paracrine BMP-2 $[163,164]$, which is considered one of the main mediators in the differentiation of MSC (and others) along the osteoblastic lineage. The putative role of pericytes as a "reservoir" of progenitor cells, as well as their potential to differentiate into several cell types, including osteoblasts, is well known $[165,166]$ and many evidences have been adduced that pericytes can undergo chondro and osteogenic differentiation [167-169]. This represents an interesting example of indirect stimulus towards calcification mediated by the synergic cross-talk between different cells of the vessel wall.

Moreover, as described previously, VW-PCs may reduce aneurysmal degeneration through the suppression of MMP expression [36]. Furthermore, VW-PC may facilitate tissue damage by differentiating into inflammatory cells. VW-PC may represent a reservoir for the localized replenishment of aneurysm wall macrophages $[33,36]$. Thus, depending on the local environment and paracrine manner via cytokines and growth factors, the VW-PC could contribute to ongoing inflammation and aneurysmal degeneration or accelerate vascular repair [170].

3.3.2. MSCs Application in Cardiovascular Regenerative Therapy: The State of the Art. VW-PCs, circulating EPCs, and umbilical cord blood cells present multiple important clinical interests. EPCs could be used to treat diverse vascular disorders because of their high migratory potential through blood and their capacity to differentiate into new endothelial cells that can contribute to promoting neoangiogenesis and endothelium repair at distant damaged tissues/organs [171, 172]. In vivo induction of mobilization of bone marrow-derived EPCs into peripheral circulation or activation of EPCs resident in vascular wall of damaged peripheral tissues could represent promising strategies to promote vascular repair of injured areas. It has been observed that EPCs were able to give rise to the endothelial cells that incorporated into the endothelial layer and this led to a reduction of the lesion size [173].

Studies have shown that the effects of MSCs upon damaged regions have been proven, causing the inhibition of local immune response, preventing excessive fibrosis, apoptosis, and inducing mitosis in intrinsic cellular progenitors [174]. These immunomodulating effects are caused by reducing the functions of B and T lymphocytes and natural killer cells, affecting the function of dendritic cells $[175,176]$. Moreover, MSCs cause a low immunogenic effect, even upon models or patients with different human leukocyte antigen (HLA), due to low expression levels of HLA-I and null expression levels of HLA-II [177-179]. Porcine models of myocardial infarction have further demonstrated the reparative potential of MSCs when administered acutely after injury [180-184]. The local injection of MSCs in a porcine model of myocardial infarction demonstrated not only the successful engraftment of locally injected MSCs but also their multiphenotypic differentiation. These are able to evolve into cells that have biologic characteristics of cardiac myocytes and endothelial cells. These findings were described along with improvement of cardiac function compared with untreated controls [185187]. The ability of postnatal skeletal muscle to repair and regenerate itself on daily physical activity or injury is well documented. However, severe pathological conditions, such as compartment syndrome and muscular dystrophy, impede structural and functional recovery mediated by myogenic progenitors and require exogenous interventions to ameliorate the progression [188-191]. Transplanted pericytes, purified from human skeletal muscle, fat, pancreas, and placenta, regenerate human myofibers in cardiotoxin-treated and dystrophic mouse muscles more efficiently than do myoblasts or endothelial cells. In addition to structural regeneration, functional recovery was demonstrated in dystrophic mice treated with pericytes isolated from muscle biopsy specimens from not only healthy adults but also, surprisingly, patients with Duchenne muscular dystrophy [192-194]. There is a linear relationship between the outcome of treatment and the type of cells applied. Osteogenic, odontoblastic, and adipogenic progenitors have also recently been shown to originate from perivascular niches in vivo, in agreement with the robust osteogenic and adipogenic properties found in purified pericytes $[195,196]$. These discoveries imply that pericytes can potentially be applied to bone regeneration, dental repair, and adipose reconstruction [197]. Higher therapeutic efficacy, including complete restoration of kidney function, was observed after infusion of cord blood (CB) MSCs/pericytes compared with regular bone marrow-derived MSCs. However, few donor cells were found in the restored area; also, it was shown in culture and in vivo that the observed renoprotective effects are mediated mainly by angiogenic and antiapoptotic factors secreted by the CB MSCs/pericytes [198, 199] and another source of stem cells is the umbilical cord 
itself [200-202]. In the perspective of cell therapies, the pericytes are mobilized and migrated toward the damaged cells, secreting high levels of antiapoptotic and angiogenic factors, such as vascular endothelial growth factor and keratinocyte growth factor. These findings suggest that pericytes can efficiently move to damaged sites and secrete growth factors that can play beneficial autocrine or paracrine roles in tissue and vascular repair [203-207]. MSCs are localized in the vascular niche in bone marrow but are also found as MSC-like cells around adult vessels (also termed pericytes and adventitial cells), and there is substantial evidence that they play a pivotal role in regulating blood vessel formation and function through multiple mechanisms such as vasculogenesis, arteriogenesis, and angiogenesis. Although MSCs or MSC-like cells have been safely used and do not pose the ethical concern of embryonic stem cells, their effects in clinical studies cannot be delineated to specific mechanisms. These might include different simultaneously acting MSC-induced mechanisms. Immunomodulation towards a more repair-friendly microenvironment, actual differentiation into vascular tissue, and paracrine or systemic release of vasculogenic, angiogenic, and/or arteriogenic-stimulating factors should in this respect be acknowledged. Additionally, the results of preclinical studies have been shown to depend not only on the model chosen and the endogenous repair capacity of the cardiovascular tissue in vivo, but also on cell source, administration route, timing of cell delivery, and cell dosage and with these specific homing and retention mechanisms. Clinical studies on necessarily heterogeneous patients add many variables (e.g., inflammatory and disease status, comorbidities, and concomitant medication) and may explain the differences in the results observed so far. MSCs markedly suppressed MMP gene expression in macrophages in vitro, MMP-2 activity ex vivo, and MMP activity in vivo and influenced TIMP1 in vivo. Negative correlations between elastin content and MMPs were confirmed [32]. MSCs also decreased expression of inflammatory cytokines, including IL-6, MCP-1, and TNFalpha which potentially may in turn lead to MMP upregulation in the aortic wall. This finding implies that MSCs might suppress the excess immunopathologic reactions in the aneurysmal vascular wall in a paracrine manner without direct cellular contact. MSCs from bone marrow have been reported to suppress dendritic cells, $\mathrm{T}$ cells, and natural killer cell activities in vitro, which may be attractive in this setting. Previous work has demonstrated that MSC mobilization and homing are induced by MMP-2, MMP-9, chemokines, or elastases. MSCs are also known to possess tropism for inflammation. Because aortic ECM degradation by MMP2 and MMP-9 and chronic inflammation of the aortic wall induced by chemokines are essential features of AAs, MSCs that likely migrate toward MMPs and chemokines have an advantage for aortic aneurysmal cell therapy $[208,209]$.

\section{Discussion}

Pathogenesis of aneurysm commonly involves inflammation, MMPs activation, ECM remodeling, and VSMC dysfunction and apoptosis, which ultimately lead to the weakening of the vessel wall and arterial expansion under the influence of mechanical forces. Rupture, dissection, and distal embolization are frequent and highly morbid complications of aneurysm [210]. The degenerative remodeling seen in arterial aneurysms can result from a combination of excessive destruction and insufficient repair; when tissue is injured, inflammatory cells infiltrate the injured area to clear damaged or dead cells and degraded proteins. Evidences have shown that SCs play an important role in tissue repair and regeneration: SCs can recruit and stimulate the proliferation of resident SCs, creating a favorable microenvironment for vascular repair [211]. Studies recently have shown VWPCs in the adventitia of ApoE-deficient mice and these progenitors contributed to experimental atherosclerosis and did not originate from the bone marrow [212, 213]. VW-PCs have been also isolated from the thoracic and abdominal aortas of humans: it was found that a subpopulation of EPCs was organized in a completely hierarchical manner in a distinct zone of vascular wall which was named as "vasculogenic zone" [16]. As mentioned above, CD34(+) cells have paracrine activity, can secrete vascular endothelial growth factor, and can promote neovascularization.

In cases of chronic inflammation such as arterial aneurysms, the local proangiogenic environment caused by activation of MMPs would induce the mobilization of local VW-PCs and tissue-resident EPCs faster than that of the circulated-EPCs or BM-EPCs and the presence of multipotent SCs at sites of aneurysm and dissection formation that can further differentiate into SMCs suggests the existence of an active repair process involving SCs. VW-PCs are relevant for the regeneration of vasa vasorum, a part of vessels which provide the blood supply for the outer layers of the vascular wall, such as the adventitia and neighbored parts of the tunica media including the "vasculogenic zone," where the VW-PCs reside.

VW-PCs not only may promote vascular repair by differentiating into vascular SMCs and fibroblasts, but also may facilitate tissue damage by differentiating into inflammatory cells. Active MMPs can induce the secretion of angiogenic cytokines such as vascular endothelial growth VEGF and stimulate host SCs proliferation and differentiation. Each of these cell types has a different function and could lead to effective repair, maladaptive remodeling, or further arterial damage.

Other several mechanisms involved in arterial aneurysms pathophysiology are hemodynamic forces (share stress); these factors are important mediators of vascular remodeling promoting arterial ECs proliferation and migration and medial SMC proliferation resulting in adaptive enlargement and luminal tortuosity. Thus, VW-PCs are innately resistant to proaneurysmal environmental stresses such as reactive oxygen species production; VSMC-PCs significantly decreased expression of MMPs and were able to attenuate formation of elastase-induced arterial aneurysms [214]. MMPs are a family of zinc dependent proteolytic enzymes that degrade various components of ECM and mediate ECM remodeling in both physiological and pathological processes. Several works reveal that proteolytic activity of MMPs controls availability of active molecules such as growth 
factors [215]: MMPs play a critical role in vascular formation and remodeling through degrading vascular basement membrane and ECM proteins and modifying angiogenic growth factors and cytokines. Both vascular formation and remodeling are complicated processes including recruitment, migration, proliferation, and apoptosis of vascular cells consisting of stem/progenitor cells, ECs, VSMCs, and other mural cells. ECM degradation and remodeling indispensable to vascular structure alterations highlight MMP functions in VSMC behaviors. MMP-2, MMP-9, MT1-MMP, MMP-3, MMP-1, and MMP-7 have been recognized in vascular tissue and play pathogenic roles in vascular remodeling via regulating VSMC behaviors [216].

Early outgrowth EPCs have limited capacity for population doubling and induce only transient angiogenesis; late outgrowth EPCs can expand to more than 100 population doublings. Early outgrowth EPCs exert an angiogenic effect mainly by secretory products, whereas late outgrowth cells were thought to produce the effect by direct engraftment. Among those were MMP-9, IL-8, macrophage migration inhibitory factor, various cathepsins and protease inhibitors, S100 proteins A11, A8, and A4, plasminogen activator inhibitor-2, and apolipoprotein $\mathrm{E}$ as well as a potent proangiogenic and prosurvival factor, and thymidine phosphorylase [217, 218].

It is possible to assume that the VW-PCs act, with different functions, in different phases of the natural history of aneurysms. In the early stages, under the auspices of the various growth factors released by the action of MMPs, the VW-PCs were associated with compensatory mechanisms that vessels oppose to lesional phenomena of their wall; in the later stages, VW-PCs may actively participate and contribute to the formation of the aneurysm, through the gradual and definitive calcification and loss of function of the arterial wall, and its rupture and dissection.

Stem cells are quiescent and reside in "stem cell niches" of the vessel wall but they become activated by insult stimuli, for example, endothelial injury by angioplasty or aneurismal development. If damage is moderate, the laminar flow will stimulate stem cells to differentiate into ECs to maintain the vessel integrity. When severe damage or atherosclerotic lesion occurs, locally the disturbed flow is induced, resulting in stem cell differentiation towards SMCs, which accumulates within the intima $[219,220]$.

The existence of VW-PCs provides an exciting prospect to directly manipulate local responses within the vasculature, as it has already happened, in a similar way, in cell therapy for critical limb ischemia [220]. In fact, several approaches such as site specific delivery and generating MMP inhibitors with increased selectivity are thought to be helpful for MMPstargeted therapy.

It could be concluded that, therapeutically, the benefit to address VW-PCs at sites of arterial aneurysms may be the possibility to predict the natural history of arterial aneurysm and frame the developmental stage of disease, studying also the behavior of the cells involved in the inflammatory process characterizing the aneurysm.

Then, addressing the specific MMPs involved in VWPCs activities, by means of specific antiproteases drugs, may prevent that the initial compensatory mechanism will be replaced by the anomalous degenerative mechanism which leads to aneurysm formation.

\section{Abbreviations}

AAA: Abdominal arterial aneurysms

ASMA: Antialpha smooth muscle action

BM-EPCs: Bone marrow-derived endothelial progenitor cells

CAD: $\quad$ C-terminal activation domain

ECM: $\quad$ Extracellular matrix

ECs: $\quad$ Endothelial cells

EGF: Epithelial growth factor

EPCs: $\quad$ Endothelial progenitor cells

FIH-1: $\quad$ Factor inhibiting HIF-1

FSP1: $\quad$ Fibroblast marker

G-CSF: Granulocyte-colony stimulating factor

GM-CSF: Granulocyte macrophage-colony

stimulating factor

HGF: Hepatocyte growth factor

HLA: Human leukocyte antigen

HIF-1: Hypoxia-inducible factor-1

HOXC11: Homeobox C11

IFN- $\gamma$ : Interferon gamma

IL-1: $\quad$ Interleukin 1

KGF: $\quad$ Keratinocyte growth factor

MAPK: Mitogen activated protein kinase

MCP-1: $\quad$ Monocyte chemoattractant protein-1

MMPs: Metalloproteinases

MSCs: Mesenchymal stem cells

MT1-MMP: Membrane type-1 metalloproteinases

NGAL: Neutrophil gelatinase-associated lipocalin

PAR-1: $\quad$ Protease-activated receptor

PDGF: $\quad$ Platelet-derived growth factor

PDGF-BB: Platelet-derived growth factor-BB

SCs: $\quad$ Stem cells

SDF1- $\alpha$ : Stromal cell derived factor 1-alpha

SM22: $\quad$ Smooth muscle cell marker 22

SMCs: $\quad$ Smooth muscle cells

TGF- $\alpha$ : Transforming growth factor alpha

TGF- $\beta$ : $\quad$ Transforming growth factor beta

TIE-2: $\quad$ Tyrosine kinase with immunoglobulin-like and EGF-like domains 2

TNF- $\alpha$ : Tumor necrosis factor alpha

VEGF: Vascular endothelial growth factor

VBM: Vascular basement membrane

VEGFR2: Vascular endothelial growth factor receptor 2

VSMCs: Vascular smooth muscle cells

VW-PCs: Vascular wall resident progenitor cells.

\section{Conflict of Interests}

The authors declare that there is no conflict of interests regarding the publication of this paper. 


\section{Authors' Contribution}

Bruno Amato participated substantially in the conception, design, and execution of the study and in the analysis and interpretation of data and also participated substantially in the drafting and editing of the paper. Rita Compagna participated substantially in conception, design, and execution of the study and in the analysis and interpretation of data and also participated substantially in the drafting and editing of the paper. Maurizio Amato participated substantially in data collection and in the analysis and interpretation of data. Raffaele Grande participated substantially in data collection and in the execution of the study and in the analysis and interpretation of data and also participated substantially in the drafting and editing of the paper. Lucia Butrico participated substantially in data collection and execution of the study and in the analysis and interpretation of data and also participated substantially in the drafting and editing of the paper. Alessio Rossi participated substantially in data collection and in the analysis and interpretation of data. Agostino Naso participated substantially in data collection and in the analysis and interpretation of data. Michele Ruggiero participated substantially in data collection and in the analysis and interpretation of data. Stefano de Franciscis participated substantially in conception, design, and execution of the study and in the analysis and interpretation of data and also participated substantially in the drafting, editing, and critical revision of the paper. Raffaele Serra participated substantially in conception, design, and execution of the study and in the analysis and interpretation of data and also participated substantially in the drafting, editing, and critical revision of the paper. Bruno Amato and Rita Compagna contributed equally to this work and share the first authorship. Stefano de Franciscis and Raffaele Serra contributed equally to this work and share the senior authorship.

\section{References}

[1] A. Pacilli and G. Pasquinelli, "Vascular wall resident progenitor cells. A review," Experimental Cell Research, vol. 315, no. 6, pp. 901-914, 2009.

[2] S. Käßmeyer, J. Plendl, P. Custodis, and M. Bahramsoltani, "New insights in vascular development: vasculogenesis and endothelial progenitor cells," Journal of Veterinary Medicine Series C: Anatomia Histologia Embryologia, vol. 38, no. 1, pp. 111, 2009.

[3] S. Ergün, D. Tilki, H.-P. Hohn, U. Gehling, and N. Kilic, "Potential implications of vascular wall resident endothelial progenitor cells," Thrombosis and Haemostasis, vol. 98, no. 5, pp. 930-939, 2007.

[4] R. Serra, G. Buffone, G. Costanzo et al., "Altered metalloproteinase-9 expression as least common denominator between varicocele, inguinal hernia, and chronic venous disorders," Annals of Vascular Surgery, vol. 28, no. 3, pp. 705-709, 2014.

[5] J. M. Barnett, G. W. McCollum, J. A. Fowler et al., "Pharmacologic and genetic manipulation of MMP-2 and -9 affects retinal neovascularization in rodent models of OIR," Investigative Ophthalmology and Visual Science, vol. 48, no. 2, pp. 907-915, 2007.
[6] A. C. Newby, "Matrix metalloproteinases regulate migration, proliferation, and death of vascular smooth muscle cells by degrading matrix and non-matrix substrates," Cardiovascular Research, vol. 69, no. 3, pp. 614-624, 2006.

[7] A. R. Williams and J. M. Hare, "Mesenchymal stem cells: biology, pathophysiology, translational findings, and therapeutic implications for cardiac disease," Circulation Research, vol. 109, no. 8, pp. 923-940, 2011.

[8] M. S. Goligorsky and P. Salven, "Concise review: endothelial stem and progenitor cells and their habitats," Stem Cells Translational Medicine, vol. 2, no. 7, pp. 499-504, 2013.

[9] E. Torsney and Q. Xu, "Resident vascular progenitor cells," Journal of Molecular and Cellular Cardiology, vol. 50, no. 2, pp. 304-311, 2011.

[10] M. E. Yeager, M. G. Frid, and K. R. Stenmark, "Progenitor cells in pulmonary vascular remodeling," Pulmonary Circulation, vol. 1, no. 1, pp. 3-16, 2011.

[11] M. Zhang, A. B. Malik, and J. Rehman, "Endothelial progenitor cells and vascular repair," Current Opinion in Hematology, vol. 21, no. 3, pp. 224-228, 2014.

[12] L. da Silva Meirelles, P. C. Chagastelles, and N. B. Nardi, "Mesenchymal stem cells reside in virtually all post-natal organs and tissues," Journal of Cell Science, vol. 119, no. 11, pp. 22042213, 2006.

[13] B. Hegyi, B. Sági, J. Kovács et al., "Identical, similar or different? Learning about immunomodulatory function of mesenchymal stem cells isolated from various mouse tissues: bone marrow, spleen, thymus and aorta wall," International Immunology, vol. 22, no. 7, pp. 551-559, 2010.

[14] D. Tilki, H.-P. Hohn, B. Ergün, S. Rafii, and S. Ergün, "Emerging biology of vascular wall progenitor cells in health and disease," Trends in Molecular Medicine, vol. 15, no. 11, pp. 501-509, 2009.

[15] G. Pasquinelli, A. Pacilli, F. Alviano et al., "Multidistrict human mesenchymal vascular cells: pluripotency and stemness characteristics," Cytotherapy, vol. 12, no. 3, pp. 275-287, 2010.

[16] D. A. Ingram, L. E. Mead, D. B. Moore, W. Woodard, A. Fenoglio, and M. C. Yoder, "Vessel wall-derived endothelial cells rapidly proliferate because they contain a complete hierarchy of endothelial progenitor cells," Blood, vol. 105, no. 7, pp. 27832786, 2005.

[17] P. Campagnolo, D. Cesselli, A. Al Haj Zen et al., "Human adult vena saphena contains perivascular progenitor cells endowed with clonogenic and proangiogenic potential," Circulation, vol. 121 , no. 15 , pp. 1735-1745, 2010.

[18] D. Klein, M. Benchellal, V. Kleff, H. G. Jakob, and S. Ergün, "Hox genes are involved in vascular wall-resident multipotent stem cell differentiation into smooth muscle cells," Scientific Reports, vol. 3, article 2178, 2013.

[19] D. Cook and P. Genever, "Regulation of mesenchymal stem cell differentiation," Advances in Experimental Medicine and Biology, vol. 786, pp. 213-229, 2013.

[20] J. N. Passman, X. R. Dong, S. P. Wu et al., "A sonic hedgehog signaling domain in the arterial adventitia supports resident Scal+ smooth muscle progenitor cells," Proceedings of the National Academy of Sciences of the United States of America, vol. 105, no. 27, pp. 9349-9354, 2008.

[21] E. Zengin, F. Chalajour, U. M. Gehling et al., "Vascular wall resident progenitor cells: a source for postnatal vasculogenesis," Development, vol. 133, no. 8, pp. 1543-1551, 2006.

[22] W. Risau, "Differentiation of endothelium," The FASEB Journal, vol. 9, no. 10, pp. 926-933, 1995. 
[23] R. K. Jain, "Molecular regulation of vessel maturation," Nature Medicine, vol. 9, no. 6, pp. 685-693, 2003.

[24] P. Carmeliet, "Manipulating angiogenesis in medicine," Journal of Internal Medicine, vol. 255, no. 5, pp. 538-561, 2004.

[25] C. Fischer, M. Schneider, and P. Carmeliet, "Principles and therapeutic implications of angiogenesis, vasculogenesis and arteriogenesis," in The Vascular Endothelium II, vol. 176 of Handbook of Experimental Pharmacology, part 2, pp. 157-212, Springer, Berlin, Germany, 2006.

[26] K. A. Moore and I. R. Lemischka, "Stem cells and their niches," Science, vol. 311, no. 5769, pp. 1880-1885, 2006.

[27] D. Ribatti, B. Nico, and E. Crivellato, "The role of pericytes in angiogenesis," International Journal of Developmental Biology, vol. 55, no. 3, pp. 261-268, 2011.

[28] E. Khmelewski, A. Becker, T. Meinertz, and W. D. Ito, “Tissue resident cells play a dominant role in arteriogenesis and concomitant macrophage accumulation," Circulation Research, vol. 95, no. 6, pp. E56-E64, 2004.

[29] M. Heil, T. Ziegelhoeffer, S. Wagner et al., "Collateral artery growth (arteriogenesis) after experimental arterial occlusion is impaired in mice lacking CC-chemokine receptor-2," Circulation Research, vol. 94, no. 5, pp. 671-677, 2004.

[30] G. Invernici, P. Madeddu, C. Emanueli, E. A. Parati, and G. Alessandri, "Human fetal aorta-derived vascular progenitor cells: identification and potential application in ischemic diseases," Cytotechnology, vol. 58, no. 1, pp. 43-47, 2008.

[31] B. Fang, Y. Li, Y. Song, and N. Li, "Isolation and characterization of multipotent progenitor cells from the human fetal aorta wall," Experimental Biology and Medicine, vol. 235, no. 1, pp. 130-138, 2010.

[32] R. Serra, R. Grande, R. Montemurro et al., "The role of matrix metalloproteinases and neutrophil gelatinase-associated lipocalin in central and peripheral arterial aneurysms," Surgery, vol. 157, no. 1, pp. 155-162, 2015.

[33] H. S. Park, G. H. Choi, S. Hahn, Y. S. Yoo, J. Y. Lee, and T. Lee, "Potential role of vascular smooth muscle cell-like progenitor cell therapy in the suppression of experimental abdominal aortic aneurysms," Biochemical and Biophysical Research Communications, vol. 431, no. 2, pp. 326-331, 2013.

[34] Z. S. Galis and J. J. Khatri, "Matrix metalloproteinases in vascular remodeling and atherogenesis: the good, the bad, and the ugly," Circulation Research, vol. 90, no. 3, pp. 251-262, 2002.

[35] N. A. Tamarina, W. D. McMillan, V. P. Shively, and W. H. Pearce, "Expression of matrix metalloproteinases and their inhibitors in aneurysms and normal aorta," Surgery, vol. 122, no. 2, pp. 264272, 1997.

[36] E. J. Ryer, R. P. Garvin, C. M. Schworer et al., "Proinflammatory role of stem cells in abdominal aortic aneurysms," Journal of Vascular Surgery, 2014.

[37] G. Pasquinelli, P. L. Tazzari, C. Vaselli et al., “Thoracic aortas from multiorgan donors are suitable for obtaining resident angiogenic mesenchymal stromal cells," Stem Cells, vol. 25, no. 7, pp. 1627-1634, 2007.

[38] G. Invernici, C. Emanueli, P. Madeddu et al., "Human fetal aorta contains vascular progenitor cells capable of inducing vasculogenesis, angiogenesis, and myogenesis in vitro and in a murine model of peripheral ischemia," The American Journal of Pathology, vol. 170, no. 6, pp. 1879-1892, 2007.

[39] C. Zhang, L. Zeng, C. Emanueli, and Q. Xu, "Blood flow and stem cells in vascular disease," Cardiovascular Research, vol. 99, no. 2, pp. 251-259, 2013.
[40] J.-I. Kawabe and N. Hasebe, "Role of the vasa vasorum and vascular resident stem cells in atherosclerosis," BioMed Research International, vol. 2014, Article ID 701571, 8 pages, 2014.

[41] Y. Hu and Q. Xu, "Adventitial biology, differentiation and function," Arteriosclerosis, Thrombosis, and Vascular Biology, vol. 31, pp. 1523-1529, 2011.

[42] D. D. Gutterman, "Adventitia-dependent influences on vascular function," American Journal of Physiology-Heart and Circulatory Physiology, vol. 277, no. 4, pp. H1265-H1272, 1999.

[43] J.-B. Michel, O. Thaunat, X. Houard, O. Meilhac, G. Caligiuri, and A. Nicoletti, "Topological determinants and consequences of adventitial responses to arterial wall injury," Arteriosclerosis, Thrombosis, and Vascular Biology, vol. 27, no. 6, pp. 1259-1268, 2007.

[44] J. N. Wilcox, E.-I. Okamoto, K.-I. Nakahara, and J. VintenJohansen, "Perivascular responses after angioplasty which may contribute to postangioplasty restenosis: a role for circulating myofibroblast precursors?" Annals of the New York Academy of Sciences, vol. 947, pp. 68-92, 2001.

[45] D. Fukuda, S. Enomoto, R. Nagai, and M. Sata, "Inhibition of renin-angiotensin system attenuates periadventitial inflammation and reduces atherosclerotic lesion formation," Biomedicine and Pharmacotherapy, vol. 63, no. 10, pp. 754-761, 2009.

[46] R. N. Mitchell and P. Libby, "Vascular remodeling in transplant vasculopathy," Circulation Research, vol. 100, no. 7, pp. 967-978, 2007.

[47] G.-P. Shi and J. S. Lindholt, "Mast cells in abdominal aortic aneurysms," Current Vascular Pharmacology, vol. 11, no. 3, pp. 314-326, 2013.

[48] K. Yoshimura, H. Aoki, Y. Ikeda et al., "Regression of abdominal aortic aneurysm by inhibition of c-Jun N-terminal kinase," Nature Medicine, vol. 11, no. 12, pp. 1330-1338, 2005.

[49] G. T. Jones, "Matrix metalloproteinases in biologic samples," Advances in Clinical Chemistry, vol. 65, pp. 199-219, 2014.

[50] M. T. Busceti, R. Grande, B. Amato et al., "Pulmonary embolism, metalloproteinases and neutrophil gelatinase associated lipocalin," Acta Phlebologica, vol. 14, no. 3, pp. 115-121, 2013.

[51] B. Amato, G. Coretti, R. Compagna et al., "Role of matrix metalloproteinases in non-healing venous ulcers," International Wound Journal, 2013.

[52] R. Serra, G. Buffone, D. Falcone et al., "Chronic venous leg ulcers are associated with high levels of metalloproteinases-9 and neutrophil gelatinase-associated lipocalin," Wound Repair and Regeneration, vol. 21, no. 3, pp. 395-401, 2013.

[53] R. Serra, R. Grande, G. Buffone, L. Gallelli, and S. de Franciscis, "The effects of minocycline on extracellular matrix in patients with chronic venous leg ulcers," Acta Phlebologica, vol. 14, no. 3, pp. 99-107, 2013.

[54] R. Serra, R. Grande, L. Butrico et al., "Effects of a new nutraceutical substance on clinical and molecular parameters in patients with chronic venous ulceration," International Wound Journal, 2014.

[55] R. Serra, L. Gallelli, A. Conti et al., "The effects of sulodexide on both clinical and molecular parameters in patients with mixed arterial and venous ulcers of lower limbs," Drug Design, Development and Therapy, vol. 8, pp. 519-527, 2014.

[56] R. Serra, R. Grande, G. Buffone et al., "Extracellular matrix assessment of infected chronic venous leg ulcers: role of metalloproteinases and inflammatory cytokines," International Wound Journal, 2014. 
[57] S. de Franciscis, L. Gallelli, L. Battaglia et al., "Cilostazol prevents foot ulcers in diabetic patients with peripheral vascular disease," International Wound Journal, 2013.

[58] S. de Franciscis, P. Mastroroberto, L. Gallelli, G. Buffone, R. Montemurro, and R. Serra, "Increased plasma levels of metalloproteinase- 9 and neutrophil gelatinaseeassociated lipocalin in a rare case of multiple artery aneurysm," Annals of Vascular Surgery, vol. 27, no. 8, pp. 1185.e5-1185.e7, 2013.

[59] R. Serra, R. Grande, L. Gallelli et al., "Carotid body paragangliomas and Matrix Metalloproteinases," Annals of Vascular Surgery, vol. 28, no. 7, pp. 1665-1670, 2014.

[60] S. de Franciscis, R. Grande, L. Butrico et al., "Resection of carotid body tumors reduces arterial blood pressure. An underestimated neuroendocrine syndrome," International Journal of Surgery, vol. 12, supplement 1, pp. S63-S67, 2014.

[61] R. Serra, R. Grande, G. Buffone et al., "Effects of glucocorticoids and TNF-alfa inhibitors on both clinical and molecular parameters in patients with Takayasu Arteritis," Journal of Pharmacology and Pharmacotherapeutics, vol. 5, no. 3, pp. 193196, 2014.

[62] R. Serra, G. Volpentesta, L. Gallelli et al., "Metalloproteinase9 and neutrophil gelatinase-associated lipocalin plasma and tissue levels evaluation in middle cerebral artery aneurysms," The British Journal of Neurosurgery, 2014.

[63] G. Bellon, L. Martiny, and A. Robinet, "Matrix metalloproteinases and matrikines in angiogenesis," Critical Reviews in Oncology/Hematology, vol. 49, no. 3, pp. 203-220, 2004.

[64] J. E. Rundhaug, "Matrix metalloproteinases and angiogenesis," Journal of Cellular and Molecular Medicine, vol. 9, no. 2, pp. 267285, 2005.

[65] B. Heissig, K. Hattori, M. Friedrich, S. Rafii, and Z. Werb, "Angiogenesis: vascular remodeling of the extracellular matrix involves metalloproteinases," Current Opinion in Hematology, vol. 10, no. 2, pp. 136-141, 2003.

[66] W. Risau, "Mechanisms of angiogenesis," Nature, vol. 386, no. 6626, pp. 671-674, 1997.

[67] P. Carmeliet, "Angiogenesis in health and disease," Nature Medicine, vol. 9, no. 6, pp. 653-660, 2003.

[68] C. Betsholtz, P. Lindblom, and H. Gerhardt, "Role of pericytes in vascular morphogenesis," EXS, no. 94, pp. 115-125, 2005.

[69] A. Armulik, G. Genové, and C. Betsholtz, "Pericytes: developmental, physiological, and pathological perspectives, problems, and promises," Developmental Cell, vol. 21, no. 2, pp. 193-215, 2011.

[70] Y. Liu and D. R. Senger, "Matrix-specific activation of Src amid Rho initiates capillary morphogenesis of endothelial cells," The FASEB Journal, vol. 18, no. 3, pp. 457-468, 2004.

[71] A. N. Stratman and G. E. Davis, "Endothelial cell-pericyte interactions stimulate basement membrane matrix assembly: influence on vascular tube remodeling, maturation, and stabilization," Microscopy and Microanalysis, vol. 18, no. 1, pp. 68-80, 2012.

[72] A. N. Stratman, K. M. Malotte, R. D. Mahan, M. J. Davis, and G. E. Davis, "Pericyte recruitment during vasculogenic tube assembly stimulates endothelial basement membrane matrix formation," Blood, vol. 114, no. 24, pp. 5091-5101, 2009.

[73] L. S. Perlmutter and H. C. Chui, "Microangiopathy, the vascular basement membrane and Alzheimer's disease: a review," Brain Research Bulletin, vol. 24, no. 5, pp. 677-686, 1990.
[74] K. Reisig and A. M. Clyne, "Fibroblast growth factor-2 binding to the endothelial basement membrane peaks at a physiologically relevant shear stress," Matrix Biology, vol. 29, no. 7, pp. 586-593, 2010.

[75] G. Nikolova, N. Jabs, I. Konstantinova et al., "The vascular basement membrane: a niche for insulin gene expression and $\beta$ cell proliferation," Developmental Cell, vol. 10, no. 3, pp. 397405, 2006.

[76] A. Soltani, D. W. Reid, S. S. Sohal et al., "Basement membrane and vascular remodelling in smokers and chronic obstructive pulmonary disease: a cross-sectional study," Respiratory Research, vol. 11, article 105, 2010.

[77] R. Wiggins, M. Goyal, S. Merritt, and P. D. Killen, "Vascular adventitial cell expression of collagen I messenger ribonucleic acid in anti-glomerular basement membrane antibody-induced crescentic nephritis in the rabbit: a cellular source for interstitial collagen synthesis in inflammatory renal disease," Laboratory Investigation, vol. 68, no. 5, pp. 557-565, 1993.

[78] A. Geevarghese and I. M. Herman, "Pericyte-endothelial crosstalk: implications and opportunities for advanced cellular therapies," Translational Research, vol. 163, no. 4, pp. 296-306, 2014.

[79] V. V. Orlova, Y. Drabsch, C. Freund et al., "Functionality of endothelial cells and pericytes from human pluripotent stem cells demonstrated in cultured vascular plexus and zebrafish xenografts," Arteriosclerosis, Thrombosis, and Vascular Biology, vol. 34, no. 1, pp. 177-186, 2014.

[80] P. Carmeliet and R. K. Jain, "Molecular mechanisms and clinical applications of angiogenesis," Nature, vol. 473, no. 7347, pp. 298307,2011

[81] X. Chen and Y. Li, "Role of matrix metalloproteinases in skeletal muscle: migration, differentiation, regeneration and fibrosis," Cell Adhesion and Migration, vol. 3, no. 4, pp. 337-341, 2009.

[82] A. Page-McCaw, A. J. Ewald, and Z. Werb, "Matrix metalloproteinases and the regulation of tissue remodelling," Nature Reviews Molecular Cell Biology, vol. 8, no. 3, pp. 221-233, 2007.

[83] J. L. Johnson, A. Dwivedi, M. Somerville, S. J. George, and A. C. Newby, "Matrix metalloproteinase (MMP)-3 activates MMP-9 mediated vascular smooth muscle cell migration and neointima formation in mice," Arteriosclerosis, Thrombosis, and Vascular Biology, vol. 31, no. 9, pp. e35-e44, 2011.

[84] E. R. Isenović, M. H. Kedees, S. Tepavčević et al., "Role of $\mathrm{PI} 3 \mathrm{~K} / \mathrm{AKT}$, cPLA2 and ERK1/2 signaling pathways in insulin regulation of vascular smooth muscle cells proliferation," Cardiovascular and Hematological Disorders-Drug Targets, vol. 9, no. 3, pp. 172-180, 2009.

[85] E. R. Isenović, S. Soskić, A. Trpković et al., "Insulin, thrombin, ERK1/2 kinase and vascular smooth muscle cells proliferation," Current Pharmaceutical Design, vol. 16, no. 35, pp. 3895-3902, 2010.

[86] K. Smiljanic, B. Obradovic, M. Obradovic, D. Nikolic, P. Marche, and E. R. Isenovic, "Involvement of the ADAM 12 in thrombin-induced rat's VSMCs proliferation," Current Medicinal Chemistry, vol. 18, no. 22, pp. 3382-3386, 2011.

[87] L. M. Matrisian and B. L. Hogan, "Growth factor-regulated proteases and extracellular matrix remodeling during mammalian development," Current topics in developmental biology, vol. 24, pp. 219-259, 1990.

[88] K. Yang, J. Palm, J. König et al., "Matrix-Metallo-Proteinases and their tissue inhibitors in radiation-induced lung injury," International Journal of Radiation Biology, vol. 83, no. 10, pp. 665-676, 2007. 
[89] N. D. Pruett, Z. Hajdu, J. Zhang et al., "Changing topographic Hox expression in blood vessels results in regionally distinct vessel wall remodeling," Biology Open, vol. 1, no. 5, pp. 430-435, 2012.

[90] J. E. Hungerford, G. K. Owens, W. S. Argraves, and C. D. Little, "Development of the aortic vessel wall as defined by vascular smooth muscle and extracellular matrix markers," Developmental Biology, vol. 178, no. 2, pp. 375-392, 1996.

[91] A. Carion, L. Benboubker, O. Hérault et al., "Stromal-derived factor 1 and matrix metalloproteinase 9 levels in bone marrow and peripheral blood of patients mobilized by granulocyte colony-stimulating factor and chemotherapy. Relationship with mobilizing capacity of haematopoietic progenitor cells," British Journal of Haematology, vol. 122, no. 6, pp. 918-926, 2003.

[92] C. Steinl, M. Essl, T. D. Schreiber et al., "Release of matrix metalloproteinase-8 during physiological trafficking and induced mobilization of human hematopoietic stem cells," Stem Cells and Development, vol. 22, no. 9, pp. 1307-1318, 2013.

[93] M. Berger, G. Bergers, B. Arnold, G. J. Hämmerling, and R. Ganss, "Regulator of G-protein signaling-5 induction in pericytes coincides with active vessel remodeling during neovascularization," Blood, vol. 105, no. 3, pp. 1094-1101, 2005.

[94] R. C. Lo, B. Lu, M. T. M. Fokkema et al., "Relative importance of aneurysm diameter and body size for predicting abdominal aortic aneurysm rupture in men and women," Journal of Vascular Surgery, vol. 59, no. 5, pp. 1209-1216, 2014.

[95] A. Farnoush, A. Avolio, and Y. Qian, "A growth model of saccular aneurysms based on hemodynamic and morphologic discriminant parameters for risk of rupture," Journal of Clinical Neuroscience, vol. 21, no. 9, pp. 1514-1519, 2014.

[96] J. Sainz, A. A. H. Zen, G. Caligiuri et al., "Isolation of 'side population' progenitor cells from healthy arteries of adult mice," Arteriosclerosis, Thrombosis, and Vascular Biology, vol. 26, no. 2, pp. 281-286, 2006.

[97] Z.-J. Liu, T. Shirakawa, Y. Li et al., "Regulation of Notch1 and Dll4 by vascular endothelial growth factor in arterial endothelial cells: Implications for modulating arteriogenesis and angiogenesis," Molecular and Cellular Biology, vol. 23, no. 1, pp. 14-25, 2003.

[98] T. Gridley, "Notch signaling in the vasculature," Current Topics in Developmental Biology, vol. 92, pp. 277-309, 2010.

[99] D. Morrow, S. Guha, C. Sweeney et al., "Notch and vascular smooth muscle cell phenotype," Circulation Research, vol. 103, no. 12, pp. 1370-1382, 2008.

[100] C. Schrimpf, O. E. Teebken, M. Wilhelmi, and J. S. Duffield, "The role of pericyte detachment in vascular rarefaction," Journal of Vascular Research, vol. 51, no. 4, pp. 247-258, 2014.

[101] C. Schrimpf and J. S. Duffield, "Mechanisms of fibrosis: the role of the pericyte," Current Opinion in Nephrology and Hypertension, vol. 20, no. 3, pp. 297-305, 2011.

[102] H. Uzui, J.-D. Lee, H. Shimizu, H. Tsutani, and T. Ueda, "The role of protein-tyrosine phosphorylation and gelatinase production in the migration and proliferation of smooth muscle cells," Atherosclerosis, vol. 149, no. 1, pp. 51-59, 2000.

[103] JCS Joint Working Group, "Guidelines for diagnosis and treatment of aortic aneurysm and aortic dissection (JCS 2011): digest version," Circulation Journal, vol. 77, no. 3, pp. 789-828, 2013.

[104] K. Ouriel, "The PIVOTAL study: a randomized comparison of endovascular repair versus surveillance in patients with smaller abdominal aortic aneurysms," Journal of Vascular Surgery, vol. 49, no. 1, pp. 266-269, 2009.
[105] L. W. van Laake, T. Vainas, R. Dammers, P. J. E. H. M. Kitslaar, A. P. G. Hoeks, and G. W. H. Schurink, "Systemic dilation diathesis in patients with abdominal aortic aneurysms: a role for matrix metalloproteinase-9?" European Journal of Vascular and Endovascular Surgery, vol. 29, no. 4, pp. 371-377, 2005.

[106] D. Mao, S. J. Van Vickle, J. A. Curci, and R. W. Thompson, "Expression of matrix metalloproteinases and TIMPs in human abdominal aortic aneurysms," Annals of Vascular Surgery, vol. 13, no. 2, pp. 236-237, 1999.

[107] W. Zhou, H. Chai, R. Ding, and H. Y. C. Lam, "Distribution of inflammatory mediators in carotid and femoral plaques," Journal of the American College of Surgeons, vol. 211, no. 1, pp. 92-98, 2010.

[108] H. R. Lijnen, "Metalloproteinases in development and progression of vascular disease," Pathophysiology of Haemostasis and Thrombosis, vol. 33, no. 5-6, pp. 275-281, 2003-2004.

[109] J. P. G. Sluijter, D. P. V. De Kleijn, and G. Pasterkamp, "Vascular remodeling and protease inhibition-bench to bedside," Cardiovascular Research, vol. 69, no. 3, pp. 595-603, 2006.

[110] M. Razavian, J. Zhang, L. Nie et al., "Molecular imaging of matrix metalloproteinase activation to predict murine aneurysm expansion in vivo," Journal of Nuclear Medicine, vol. 51, no. 7, pp. 1107-1115, 2010.

[111] T. Higashikata, M. Yamagishi, T. Higashi et al., "Altered expression balance of matrix metalloproteinases and their inhibitors in human carotid plaque disruption: results of quantitative tissue analysis using real-time RT-PCR method," Atherosclerosis, vol. 185, no. 1, pp. 165-172, 2006.

[112] N. Fiotti, N. Altamura, M. Fisicaro et al., "MMP-9 microsatellite polymorphism: association with the progression of intimamedia thickening and constrictive remodeling of carotid atherosclerotic plaques," Atherosclerosis, vol. 182, no. 2, pp. 287292, 2005.

[113] A. Buss, K. Pech, S. Roelver, B. Bloemeke, C. Klotzsch, and S. Breuer, "Functional polymorphisms in matrix metalloproteinases $-1,-3,-9$ and -12 in relation to cervical artery dissection," BMC Neurology, vol. 9, article 40, 2009.

[114] T. Sandgren, B. Sonesson, A. R. Ahlgren, and T. Länne, "The diameter of the common femoral artery in healthy human: influence of sex, age, and body size," Journal of Vascular Surgery, vol. 29, no. 3, pp. 503-510, 1999.

[115] R. Debasso, H. Astrand, N. Bjarnegård, A. R. Ahlgren, T. Sandgren, and T. Länne, "The popliteal artery, an unusual muscular artery with wall properties similar to the aorta: implications for susceptibility to aneurysm formation?" Journal of Vascular Surgery, vol. 39, no. 4, pp. 836-842, 2004.

[116] H. Abdul-Hussien, R. Hanemaaijer, R. Kleemann, B. F. J. Verhaaren, J. H. van Bockel, and J. H. N. Lindeman, "The pathophysiology of abdominal aortic aneurysm growth: corresponding and discordant inflammatory and proteolytic processes in abdominal aortic and popliteal artery aneurysms," Journal of Vascular Surgery, vol. 51, no. 6, pp. 1479-1487, 2010.

[117] R. Hurks, R. H. Kropman, C. W. Pennekamp et al., "RR28. Wall composition of popliteal artery aneurysms differs from abdominal aortic aneurysms," Journal of Vascular Surgery, vol. 51, no. 6, supplement, p. 100S, 2010.

[118] J. C. McDaniel, S. Roy, and T. A. Wilgus, "Neutrophil activity in chronic venous leg ulcers-a target for therapy?" Wound Repair and Regeneration, vol. 21, no. 3, pp. 339-351, 2013.

[119] R. Serra, L. Gallelli, G. Buffone et al., "Doxycycline speeds up healing of chronic venous ulcers," International Wound Journal, 2013. 
[120] M. Marco, C. Fortin, and T. Fulop, "Membrane-type matrix metalloproteinases: key mediators of leukocyte function," Journal of Leukocyte Biology, vol. 94, no. 2, pp. 237-246, 2013.

[121] D. Sbardella, G. F. Fasciglione, M. Gioia et al., "Human matrix metalloproteinases: an ubiquitarian class of enzymes involved in several pathological processes," Molecular Aspects of Medicine, vol. 33, no. 2, pp. 119-208, 2012.

[122] A. Bobik and V. Tkachuk, "Metalloproteinases and plasminogen activators in vessel remodeling," Current Hypertension Reports, vol. 5, no. 6, pp. 466-472, 2003.

[123] J. A. Rodriguez, J. Orbe, S. M. de Lizarrondo et al., "Metalloproteinases and atherothrombosis: MMP-10 mediates vascular remodeling promoted by inflammatory stimuli," Frontiers in Bioscience, vol. 13, no. 8, pp. 2916-2921, 2008.

[124] R. Kadirvel, Y.-H. Ding, D. Dai et al., "The influence of hemodynamic forces on biomarkers in the walls of elastaseinduced aneurysms in rabbits," Neuroradiology, vol. 49, no. 12, pp. 1041-1053, 2007.

[125] G. Dormn, S. Cseh, I. Hajd et al., "Matrix metalloproteinase inhibitors: a critical appraisal of design principles and proposed therapeutic utility," Drugs, vol. 70, no. 8, pp. 949-964, 2010.

[126] J. Hu, P. E. van den Steen, Q.-X. A. Sang, and G. Opdenakker, "Matrix metalloproteinase inhibitors as therapy for inflammatory and vascular diseases," Nature Reviews Drug Discovery, vol. 6, no. 6, pp. 480-498, 2007.

[127] J. T. Witte, J. E. Hasson, B. A. Harms, T. E. Corrigan, and R. B. Love, "Fatal gastric artery dissection and rupture occurring as a paraesophageal mass: a case report and literature review," Surgery, vol. 107, no. 5, pp. 590-594, 1990.

[128] Y. H. Shen, X. Hu, S. Zou, D. Wu, J. S. Coselli, and S. A. Lemaire, "Stem cells in thoracic aortic aneurysms and dissections: potential contributors to aortic repair," Annals of Thoracic Surgery, vol. 93, no. 5, pp. 1524-1533, 2012.

[129] J. A. Curci and R. W. Thompson, "Adaptive cellular immunity in aortic aneurysms: cause, consequence, or context?" The Journal of Clinical Investigation, vol. 114, no. 2, pp. 168-171, 2004.

[130] W. Xiong, Y. Zhao, A. Prall, T. C. Greiner, and B. T. Baxter, "Key roles of $\mathrm{CD}^{+} \mathrm{T}$ cells and IFN-gamma in the development of abdominal aortic aneurysms in a murine model," Journal of Immunology, vol. 172, no. 4, pp. 2607-2612, 2004.

[131] G. M. Longo, W. Xiong, T. C. Greiner, Y. Zhao, N. Fiotti, and B. T. Baxter, "Matrix metalloproteinases 2 and 9 work in concert to produce aortic aneurysms," The Journal of Clinical Investigation, vol. 110, no. 5, pp. 625-632, 2002.

[132] J. S. Ikonomidis, J. R. Barbour, Z. Amani et al., "Effects of deletion of the matrix metalloproteinase 9 gene on development of murine thoracic aortic aneurysms," Circulation, vol. 112, no. 9, supplement, pp. I242-I248, 2005.

[133] Q. Mao, C.-X. Lin, X.-L. Liang, J.-S. Gao, and B. Xu, "Mesenchymal stem cells overexpressing integrin-linked kinase attenuate cardiac fibroblast proliferation and collagen synthesis through paracrine actions," Molecular Medicine Reports, vol. 7, no. 5, pp. 1617-1623, 2013.

[134] K. A. Cieslik, J. Trial, J. R. Crawford, G. E. Taffet, and M. L. Entman, "Adverse fibrosis in the aging heart depends on signaling between myeloid and mesenchymal cells; role of inflammatory fibroblasts," Journal of Molecular and Cellular Cardiology, vol. 70, pp. 56-63, 2014.

[135] N. W. M. Ramnath, K. M. van de Luijtgaarden, I. van der Pluijm et al., "Extracellular matrix defects in aneurysmal Fibulin-4 mice predispose to lung emphysema," PLoS ONE, vol. 9, no. 9, Article ID e106054, 2014.
[136] O. Yamashita, K. Yoshimura, A. Nagasawa et al., "Periostin links mechanical strain to inflammation in abdominal aortic aneurysm," PLoS ONE, vol. 8, no. 11, Article ID e79753, 2013.

[137] H. Tazume, K. Miyata, Z. Tian et al., "Macrophage-derived angiopoietin-like protein 2 accelerates development of abdominal aortic aneurysm," Arteriosclerosis, Thrombosis, and Vascular Biology, vol. 32, no. 6, pp. 1400-1409, 2012.

[138] D. Klein, P. Weißhardt, V. Kleff, H. Jastrow, H. G. Jakob, and S. Ergün, "Vascular wall-resident CD44+ multipotent stem cells give rise to pericytes and smooth muscle cells and contribute to new vessel maturation," PLoS ONE, vol. 6, no. 5, Article ID e20540, 2011.

[139] T. Chan-Ling, M. E. Koina, J. R. McColm et al., "Role of $\mathrm{CD} 44^{+}$stem cells in mural cell formation in the human choroid: evidence of vascular instability due to limited pericyte ensheathment," Investigative Ophthalmology and Visual Science, vol. 52, no. 1, pp. 399-410, 2011.

[140] F. Vasuri, S. Fittipaldi, and G. Pasquinelli, "Arterial calcification: finger-pointing at resident and circulating stem cells," World Journal of Stem Cells, vol. 6, no. 5, pp. 540-551, 2014.

[141] Y. Hu, Z. Zhang, E. Torsney et al., "Abundant progenitor cells in the adventitia contribute to atheroscleroses of vein grafts in ApoE-deficient mice," The Journal of Clinical Investigation, vol. 113, no. 9, pp. 1258-1265, 2004.

[142] E. Torsney, Y. Hu, and Q. Xu, "Adventitial progenitor cells contribute to arteriosclerosis," Trends in Cardiovascular Medicine, vol. 15, no. 2, pp. 64-68, 2005.

[143] A. Margariti, L. Zeng, and Q. Xu, "Stem cells, vascular smooth muscle cells and atherosclerosis," Histology and Histopathology, vol. 21, no. 7-9, pp. 979-985, 2006.

[144] E. Torsney, K. Mandal, A. Halliday, M. Jahangiri, and Q. Xu, "Characterisation of progenitor cells in human atherosclerotic vessels," Atherosclerosis, vol. 191, no. 2, pp. 259-264, 2007.

[145] U. Tigges, M. Komatsu, and W. B. Stallcup, "Adventitial pericyte progenitor/mesenchymal stem cells participate in the restenotic response to arterial injury," Journal of Vascular Research, vol. 50, no. 2, pp. 134-144, 2013.

[146] M. K. Grudzinska, E. Kurzejamska, K. Bojakowski et al., "Monocyte chemoattractant protein 1-mediated migration of mesenchymal stem cells is a source of intimal hyperplasia," Arteriosclerosis, Thrombosis, and Vascular Biology, vol. 33, no. 6, pp. 1271-1279, 2013.

[147] Y. Si, J. Ren, P. Wang et al., "Protein kinase C-delta mediates adventitial cell migration through regulation of monocyte chemoattractant protein-1 expression in a rat angioplasty model," Arteriosclerosis, Thrombosis, and Vascular Biology, vol. 32, no. 4, pp. 943-954, 2012.

[148] X.-L. Ma, K.-D. Liu, F.-C. Li, X.-M. Jiang, L. Jiang, and H.-L. $\mathrm{Li}$, "Human mesenchymal stem cells increases expression of $\alpha$ tubulin and angiopoietin 1 and 2 in focal cerebral ischemia and reperfusion," Current Neurovascular Research, vol. 10, no. 2, pp. 103-111, 2013.

[149] T. Onda, O. Honmou, K. Harada, K. Houkin, H. Hamada, and J. D. Kocsis, "Therapeutic benefits by human mesenchymal stem cells (hMSCs) and Ang-1 gene-modified hMSCs after cerebral ischemia," Journal of Cerebral Blood Flow and Metabolism, vol. 28, no. 2, pp. 329-340, 2008.

[150] G. Tellides and J. S. Pober, "Inflammatory and immune responses in the arterial media," Circulation Research, vol. 116, no. 2, pp. 312-322, 2015.

[151] P. Lacolley, V. Regnault, A. Nicoletti, Z. Li, and J.-B. Michel, “The vascular smooth muscle cell in arterial pathology: a cell that can 
take on multiple roles," Cardiovascular Research, vol. 95, no. 2, pp. 194-204, 2012.

[152] A. D. Luster, R. Alon, and U. H. von Andrian, "Immune cell migration in inflammation: present and future therapeutic targets," Nature Immunology, vol. 6, no. 12, pp. 1182-1190, 2005.

[153] P. Friedl and B. Weigelin, "Interstitial leukocyte migration and immune function," Nature Immunology, vol. 9, no. 9, pp. 960969, 2008.

[154] S. Ma, N. Xie, W. Li, B. Yuan, Y. Shi, and Y. Wang, "Immunobiology of mesenchymal stem cells," Cell Death and Differentiation, vol. 21, no. 2, pp. 216-225, 2014.

[155] Y. Shi, J. Su, A. I. Roberts, P. Shou, A. B. Rabson, and G. Ren, "How mesenchymal stem cells interact with tissue immune responses," Trends in Immunology, vol. 33, no. 3, pp. 136-143, 2012.

[156] M. Kassem, B. M. Abdallah, and H. Saeed, "Osteoblastic cells: differentiation and trans-differentiation," Archives of Biochemistry and Biophysics, vol. 473, no. 2, pp. 183-187, 2008.

[157] M. Sata, K. Tanaka, and R. Nagai, "Circulating osteoblastlineage cells," The New England Journal of Medicine, vol. 353, no. 7, pp. 737-738, 2005.

[158] R. J. Pignolo and E. M. Shore, "Circulating osteogenic precursor cells," Critical Reviews in Eukaryotic Gene Expression, vol. 20, no. 2, pp. 171-180, 2010.

[159] R. C. Rennert, M. Sorkin, R. K. Garg, and G. C. Gurtner, "Stem cell recruitment after injury: lessons for regenerative medicine," Regenerative Medicine, vol. 7, no. 6, pp. 833-850, 2012.

[160] I. Bertoncello and J. L. Mcqualter, "Endogenous lung stem cells: what is their potential for use in regenerative medicine?" Expert Review of Respiratory Medicine, vol. 4, no. 3, pp. 349-362, 2010.

[161] S. Guan, Z. Wang, F. Xin, and H. Xin, "Wnt5a is associated with the differentiation of bone marrow mesenchymal stem cells in vascular calcification by connecting with different receptors," Molecular Medicine Reports, vol. 10, no. 4, pp. 1985-1991, 2014.

[162] I. Endo and T. Mastumoto, "Bone and stem cells. Regulatory mechanism of mesenchymal stem cell differentiation to osteoblasts," Clinical Calcium, vol. 24, no. 4, pp. 555-564, 2014.

[163] A. Callegari, M. L. Coons, J. L. Ricks et al., "Bone marrowor vessel wall-derived osteoprotegerin is sufficient to reduce atherosclerotic lesion size and vascular calcification," Arteriosclerosis, Thrombosis, and Vascular Biology, vol. 33, no. 11, pp. 2491-2500, 2013.

[164] A. P. Sage, Y. Tintut, and L. L. Demer, "Regulatory mechanisms in vascular calcification," Nature Reviews Cardiology, vol. 7, no. 9, pp. 528-536, 2010.

[165] C. M. Shanahan, N. R. B. Cary, J. R. Salisbury, D. Proudfoot, P. L. Weissberg, and M. E. Edmonds, "Medial localization of mineralization-regulating proteins in association with Mönckeberg's sclerosis: evidence for smooth muscle cellmediated vascular calcification," Circulation, vol. 100, no. 21, pp. 2168-2176, 1999.

[166] K. L. Tyson, J. L. Reynolds, R. McNair, Q. Zhang, P. L. Weissberg, and C. M. Shanahan, "Osteo/chondrocytic transcription factors and their target genes exhibit distinct patterns of expression in human arterial calcification," Arteriosclerosis, Thrombosis, and Vascular Biology, vol. 23, no. 3, pp. 489-494, 2003.

[167] C. T. Brighton, D. G. Lorich, R. Kupcha, T. M. Reilly, A. R. Jones, and R. A. Woodbury II, "The pericyte as a possible osteoblast progenitor cell," Clinical Orthopaedics and Related Research, no. 275, pp. 287-299, 1992.
[168] L. Diaz-Flores, R. Gutierrez, A. Lopez-Alonso, R. Gonzalez, and H. Varela, "Pericytes as a supplementary source of osteoblasts in periosteal osteogenesis," Clinical Orthopaedics and Related Research, no. 275, pp. 280-286, 1992.

[169] L. Díaz-Flores, R. Gutiérrez, J. F. Madrid et al., "Pericytes. Morphofunction, interactions and pathology in a quiescent and activated mesenchymal cell niche," Histology and Histopathology, vol. 24, no. 7, pp. 909-969, 2009.

[170] J. Liu, W. Xiong, L. Baca-Regen, H. Nagase, and B. T. Baxter, "Mechanism of inhibition of matrix metalloproteinase-2 expression by doxycycline in human aortic smooth muscle cells," Journal of Vascular Surgery, vol. 38, no. 6, pp. 1376-1383, 2003.

[171] P. Müller, A. P. Beltrami, D. Cesselli, P. Pfeiffer, A. Kazakov, and M. Böhm, "Myocardial regeneration by endogenous adult progenitor cells," Journal of Molecular and Cellular Cardiology, vol. 39, no. 2, pp. 377-387, 2005.

[172] X. Xie, A. Sun, Z. Huang et al., "Another possible cell source for cardiac regenerative medicine: reprogramming adult fibroblasts to cardiomyocytes and endothelial progenitor cells," Medical Hypotheses, vol. 76, no. 3, pp. 365-367, 2011.

[173] E. B. Friedrich, K. Walenta, J. Scharlau, G. Nickenig, and N. Werner, "CD34 ${ }^{-} / \mathrm{CD} 133^{+} / \mathrm{VEGFR}-2^{+}$endothelial progenitor cell subpopulation with potent vasoregenerative capacities," Circulation Research, vol. 98, no. 3, pp. e20-e25, 2006.

[174] A. Trollope, J. V. Moxon, C. S. Moran, and J. Golledge, "Animal models of abdominal aortic aneurysm and their role in furthering management of human disease," Cardiovascular Pathology, vol. 20, no. 2, pp. 114-123, 2011.

[175] A. Uccelli, L. Moretta, and V. Pistoia, "Immunoregulatory function of mesenchymal stem cells," European Journal of Immunology, vol. 36, no. 10, pp. 2566-2573, 2006.

[176] J. Kiss, V. S. Urbán, V. Dudics, V. Vas, and F. Uher, "Mesenchymal stem cells and the immune system-immunosuppression without drugs?" Orvosi Hetilap, vol. 149, no. 8, pp. 339-346, 2008.

[177] V. Planat-Benard, J.-S. Silvestre, B. Cousin et al., "Plasticity of human adipose lineage cells toward endothelial cells: physiological and therapeutic perspectives," Circulation, vol. 109, no. 5, pp. 656-663, 2004.

[178] H. Nakagami, K. Maeda, R. Morishita et al., "Novel autologous cell therapy in ischemic limb disease through growth factor secretion by cultured adipose tissue-derived stromal cells," Arteriosclerosis, Thrombosis, and Vascular Biology, vol. 25, no. 12, pp. 2542-2547, 2005.

[179] A. Miranville, C. Heeschen, C. Sengenès, C. A. Curat, R. Busse, and A. Bouloumié, "Improvement of postnatal neovascularization by human adipose tissue-derived stem cells," Circulation, vol. 110, no. 3, pp. 349-355, 2004.

[180] H. K. Grøgaard, O. E. Sigurjonsson, M. Brekke et al., "Cardiac accumulation of bone marrow mononuclear progenitor cells after intracoronary or intravenous injection in pigs subjected to acute myocardial infarction with subsequent reperfusion," Cardiovascular Revascularization Medicine, vol. 8, no. 1, pp. 2127, 2007.

[181] R. J. Henning, "Stem cells in cardiac repair," Future Cardiology, vol. 7, no. 1, pp. 99-117, 2011.

[182] Z. Yang, F. Zhang, W. Ma et al., "A novel approach to transplanting bone marrow stem cells to repair human myocardial infarction: delivery via a noninfarct-relative artery," Cardiovascular Therapeutics, vol. 28, no. 6, pp. 380-385, 2010. 
[183] M. M. Lalu, L. McIntyre, C. Pugliese et al., "Safety of cell therapy with mesenchymal stromal cells (SafeCell): a systematic review and meta-analysis of clinical trials," PLoS ONE, vol. 7, no. 10, Article ID e47559, 2012.

[184] A. R. Williams, K. E. Hatzistergos, B. Addicott et al., "Enhanced effect of combining human cardiac stem cells and bone marrow mesenchymal stem cells to reduce infarct size and to restore cardiac function after myocardial infarction," Circulation, vol. 127, no. 2, pp. 213-223, 2013.

[185] A. R. Williams, K. E. Hatzistergos, B. Addicott et al., "Enhanced effect of combining human cardiac stem cells and bone marrow mesenchymal stem cells to reduce infarct size and to restore cardiac function after myocardial infarction," Circulation, vol. 127, no. 2, pp. 213-223, 2013.

[186] B. N. Oskouei, G. Lamirault, C. Joseph et al., "Increased potency of cardiac stem cells compared with bone marrow mesenchymal stem cells in cardiac repair," Stem Cells Translational Medicine, vol. 1, no. 2, pp. 116-124, 2012.

[187] X.-L. Tang, D. G. Rokosh, Y. Guo, and R. Bolli, "Cardiac progenitor cells and bone marrow-derived very small embryoniclike stem cells for cardiac repair after myocardial infarction," Circulation Journal, vol. 74, no. 3, pp. 390-404, 2010.

[188] B. Péault, M. Rudnicki, Y. Torrente et al., "Stem and progenitor cells in skeletal muscle development, maintenance, and therapy," Molecular Therapy, vol. 15, no. 5, pp. 867-877, 2007.

[189] K. J. Mitchell, A. Pannérec, B. Cadot et al., "Identification and characterization of a non-satellite cell muscle resident progenitor during postnatal development," Nature Cell Biology, vol. 12, no. 3, pp. 257-266, 2010.

[190] G. Q. Wallace and E. M. McNally, "Mechanisms of muscle degeneration, regeneration, and repair in the muscular dystrophies," Annual Review of Physiology, vol. 71, pp. 37-57, 2009.

[191] F. Rahimov and L. M. Kunkel, "Cellular and molecular mechanisms underlying muscular dystrophy," Journal of Cell Biology, vol. 201, no. 4, pp. 499-510, 2013.

[192] M. Corselli, C.-W. Chen, M. Crisan, L. Lazzari, and B. Péault, "Perivascular ancestors of adult multipotent stem cells," Arteriosclerosis, Thrombosis, and Vascular Biology, vol. 30, no. 6, pp. 1104-1109, 2010.

[193] A. Dellavalle, M. Sampaolesi, R. Tonlorenzi et al., "Pericytes of human skeletal muscle are myogenic precursors distinct from satellite cells," Nature Cell Biology, vol. 9, no. 3, pp. 255-267, 2007.

[194] A. Farini, P. Razini, S. Erratico, Y. Torrente, and M. Meregalli, "Cell based therapy for duchenne muscular dystrophy," Journal of Cellular Physiology, vol. 221, no. 3, pp. 526-534, 2009.

[195] G. T.-J. Huang, T. Yamaza, L. D. Shea et al., "Stem/progenitor cell-mediated de novo regeneration of dental pulp with newly deposited continuous layer of dentin in an in vivo model," Tissue Engineering Part A, vol. 16, no. 2, pp. 605-615, 2010.

[196] P. Bianco, B. Sacchetti, and M. Riminucci, "Osteoprogenitors and the hematopoietic microenvironment," Best Practice and Research: Clinical Haematology, vol. 24, no. 1, pp. 37-47, 2011.

[197] S. Shi and S. Gronthos, "Perivascular niche of postnatal mesenchymal stem cells in human bone marrow and dental pulp," Journal of Bone and Mineral Research, vol. 18, no. 4, pp. 696-704, 2003.

[198] M. Morigi, C. Rota, T. Montemurro et al., "Life-sparing effect of human cord blood-mesenchymal stem cells in experimental acute kidney injury," Stem Cells, vol. 28, no. 3, pp. 513-522, 2010.

[199] H. Asanuma, D. R. Meldrum, and K. K. Meldrum, "Therapeutic applications of mesenchymal stem cells to repair kidney injury," Journal of Urology, vol. 184, no. 1, pp. 26-33, 2010.
[200] R. R. Pochampally, J. R. Smith, J. Ylostalo, and D. J. Prockop, "Serum deprivation of human marrow stromal cells (hMSCs) selects for a subpopulation of early progenitor cells with enhanced expression of OCT-4 and other embryonic genes," Blood, vol. 103, no. 5, pp. 1647-1652, 2004.

[201] D. Ibberson, N. Tremain, A. Gray, and D. G. Phinney, "What is in a name? Defining the molecular phenotype of marrow stromal cells and their relationship to other stem/progenitor cells," Cytotherapy, vol. 3, no. 5, pp. 409-411, 2001.

[202] V. F. la Russa, P. Schwarzenberger, A. Miller, K. Agrawal, J. Kolls, and R. Weiner, "Marrow stem cells, mesenchymal progenitor cells, and stromal progeny," Cancer Investigation, vol. 20, no. 1, pp. 110-123, 2002.

[203] T. Montemurro, G. Andriolo, E. Montelatici et al., "Differentiation and migration properties of human foetal umbilical cord perivascular cells: potential for lung repair," Journal of Cellular and Molecular Medicine, vol. 15, no. 4, pp. 796-808, 2011.

[204] D. T. Covas, R. A. Panepucci, A. M. Fontes et al., "Multipotent mesenchymal stromal cells obtained from diverse human tissues share functional properties and gene-expression profile with $\mathrm{CD}_{146^{+}}$perivascular cells and fibroblasts," Experimental Hematology, vol. 36, no. 5, pp. 642-654, 2008.

[205] R. Schweizer, P. Kamat, D. Schweizer et al., "Bone marrowderived mesenchymal stromal cells improve vascular regeneration and reduce leukocyte-endothelium activation in critical ischemic murine skin in a dose-dependent manner," Cytotherapy, vol. 16, no. 10, pp. 1345-1360, 2014.

[206] F. Bortolotti, L. Ukovich, V. Razban et al., "In vivo therapeutic potential of mesenchymal stromal cells depends on the source and the isolation procedure," Stem Cell Reports, 2015.

[207] S. M. Watt, F. Gullo, M. van der Garde et al., "The angiogenic properties of mesenchymal stem/stromal cells and their therapeutic potential," British Medical Bulletin, vol. 108, no. 1, pp. 25-53, 2013.

[208] R. Hashizume, A. Yamawaki-Ogata, Y. Ueda, W. R. Wagner, and Y. Narita, "Mesenchymal stem cells attenuate angiotensin IIinduced aortic aneurysm growth in apolipoprotein E-deficient mice," Journal of Vascular Surgery, vol. 54, no. 6, pp. 1743-1752, 2011.

[209] D. J. Prockop and J. Youn Oh, "Mesenchymal stem/stromal cells (MSCs): role as guardians of inflammation," Molecular Therapy, vol. 20, no. 1, pp. 14-20, 2012.

[210] W. S. Aronow, "Peripheral arterial disease and abdominal aortic aneurysm in elderly people," Minerva Medica, vol. 102, no. 6, pp. 483-500, 2011.

[211] R. Kraemer, H. Nguyen, K. L. March, and B. Hempstead, "NGF activates similar intracellular signaling pathways in vascular smooth muscle cells as PDGF-BB but elicits different biological responses," Arteriosclerosis, Thrombosis, and Vascular Biology, vol. 19, no. 4, pp. 1041-1050, 1999.

[212] Y. Hu, Z. Zhang, E. Torsney et al., "Abundant progenitor cells in the adventitia contribute to atherosclerosis of vein grafts in ApoE-deficient mice," The Journal of Clinical Investigation, vol. 113, no. 9, pp. 1258-1265, 2004.

[213] M. Mayr, A. Zampetaki, A. Sidibe et al., "Proteomic and metabolomic analysis of smooth muscle cells derived from the arterial media and adventitial progenitors of apolipoprotein Edeficient mice," Circulation Research, vol. 102, no. 9, pp. 10461056, 2008.

[214] G. Matthew Longo, W. Xiong, T. C. Greiner, Y. Zhao, N. Fiotti, and B. Timothy Baxter, "Matrix metalloproteinases 2 and 9 work 
in concert to produce aortic aneurysms," Journal of Clinical Investigation, vol. 110, no. 5, pp. 625-632, 2002.

[215] M. D. Sternlicht and Z. Werb, "How matrix metalloproteinases regulate cell behavior," Annual Review of Cell and Developmental Biology, vol. 17, pp. 463-516, 2001.

[216] J. D. Raffetto and R. A. Khalil, "Matrix metalloproteinases and their inhibitors in vascular remodeling and vascular disease," Biochemical Pharmacology, vol. 75, no. 2, pp. 346-359, 2008.

[217] I. R. Murray, C. C. West, W. R. Hardy et al., "Natural history of mesenchymal stem cells, from vessel walls to culture vessels," Cellular and Molecular Life Sciences, vol. 71, no. 8, pp. 1353-1374, 2014.

[218] C. Chaabane, F. Otsuka, R. Virmani, and M.-L. BochatonPiallat, "Biological responses in stented arteries," Cardiovascular Research, vol. 99, no. 2, pp. 353-363, 2013.

[219] C. Zgheib, J. Xu, and K. W. Liechty, "Targeting inflammatory cytokines and extracellular matrix composition to promote wound regeneration," Advances in Wound Care, vol. 3, no. 4, pp. 344-355, 2014.

[220] R. Compagna, B. Amato, S. Massa et al., "Cell therapy in patients with critical limb ischemia," Stem Cells International. In press. 

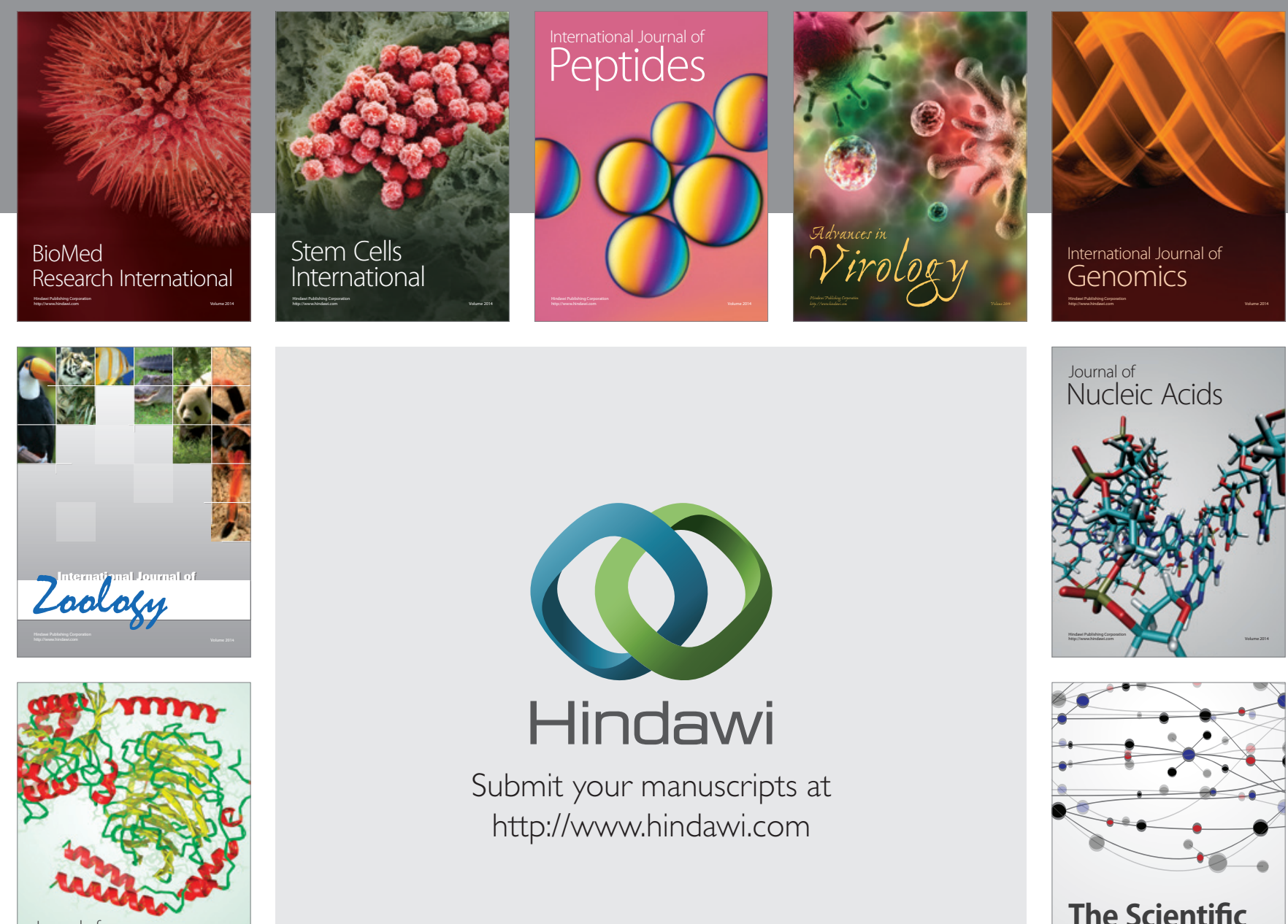

Submit your manuscripts at

http://www.hindawi.com

Journal of
Signal Transduction
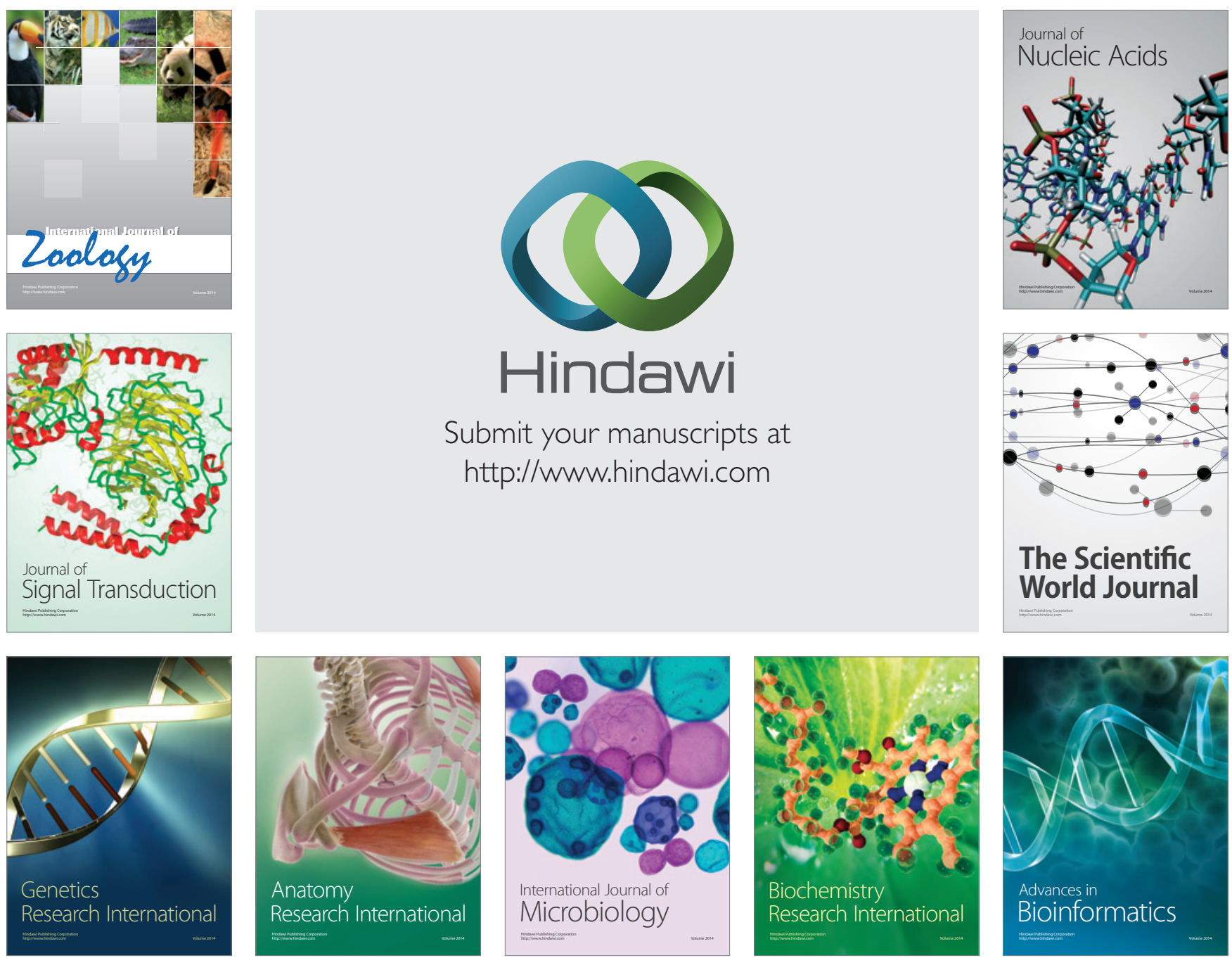

The Scientific World Journal
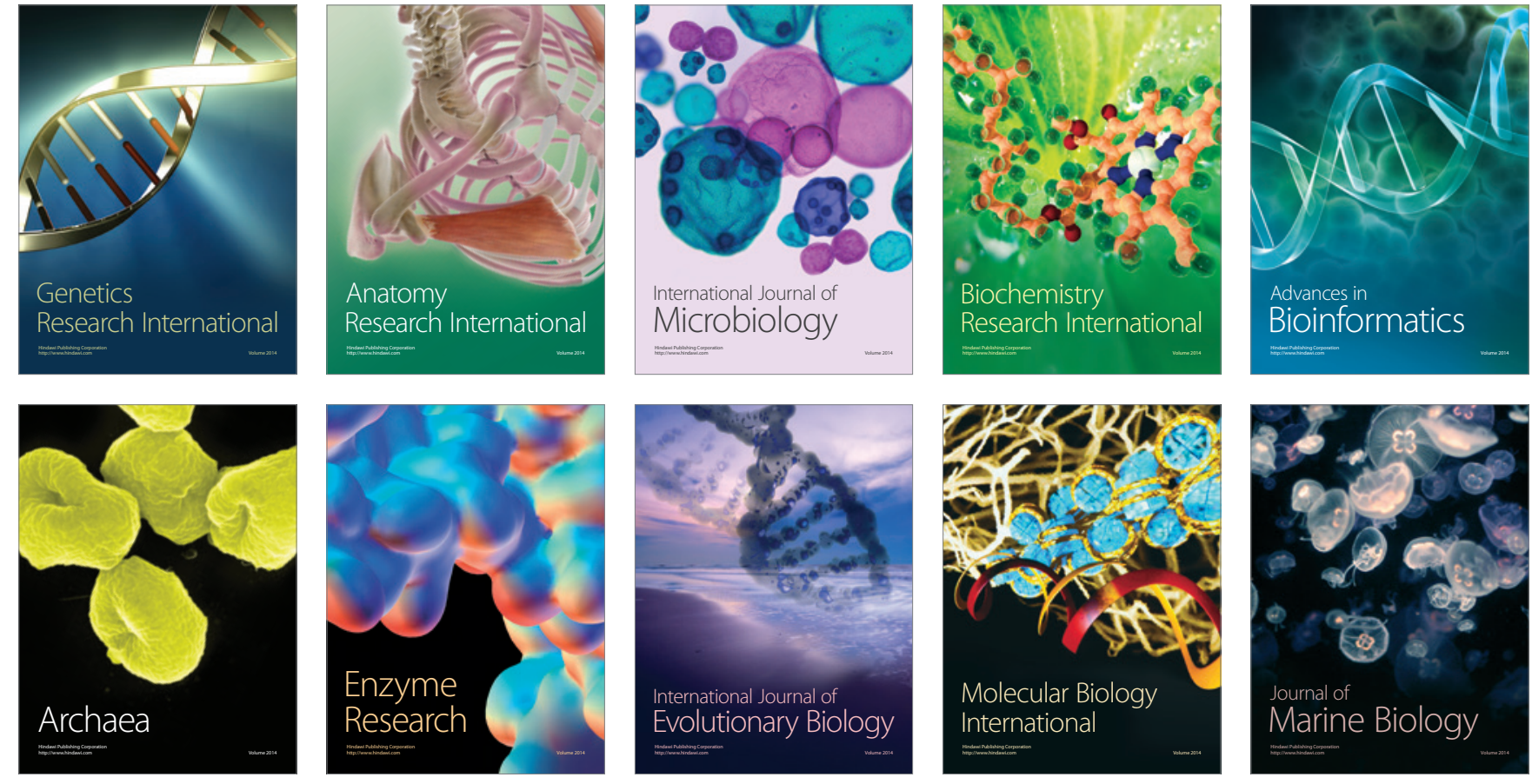